University of Massachusetts Amherst

ScholarWorks@UMass Amherst

November 2015

\title{
The Influence of Expectancy Persuasion Techniques on Socially Anxious Analogue Patients' Treatment Beliefs and Therapeutic Actions
}

Rebecca M. Ametrano

University of Massachusetts Amherst

Follow this and additional works at: https://scholarworks.umass.edu/dissertations_2

Part of the Clinical Psychology Commons

\section{Recommended Citation}

Ametrano, Rebecca M., "The Influence of Expectancy Persuasion Techniques on Socially Anxious Analogue Patients' Treatment Beliefs and Therapeutic Actions" (2015). Doctoral Dissertations. 418.

https://doi.org/10.7275/6899084.0 https://scholarworks.umass.edu/dissertations_2/418

This Open Access Dissertation is brought to you for free and open access by the Dissertations and Theses at ScholarWorks@UMass Amherst. It has been accepted for inclusion in Doctoral Dissertations by an authorized administrator of ScholarWorks@UMass Amherst. For more information, please contact scholarworks@library.umass.edu. 


\title{
THE INFLUENCE OF EXPECTANCY PERSUASION TECHNIQUES ON SOCIALLY ANXIOUS ANALOGUE PATIENTS' TREATMENT BELIEFS AND THERAPEUTIC ACTIONS
}

\author{
A Dissertation Presented \\ by \\ REBECCA M. AMETRANO
}

\author{
Submitted to the Graduate School of the \\ University of Massachusetts Amherst in partial fulfillment \\ of the requirements for the degree of
}

DOCTOR OF PHILOSOPHY

September 2015

Psychology

Clinical Psychology 

(C) Copyright by Rebecca M. Ametrano 2015 All Rights Reserved 
The Influence of Expectancy Persuasion Techniques on Socially Anxious Analogue

Patients' Treatment Beliefs and Therapeutic Actions

A Dissertation Presented

by

REBECCA M. AMETRANO

Approved as to style and content by:

Michael J. Constantino, Chair

Elizabeth Harvey, Member

Ronnie Janoff-Bulman, Member

William Matthews, Member

Hal Grotevant, Department Chair

Department of Psychological and Brain Sciences 


\section{DEDICATION}

For David and Irene who inspired me to become a psychologist. 


\section{ACKNOWLEDGEMENTS}

First, I want to acknowledge my dissertation chair and mentor, Michael Constantino. It goes without saying that I would not have completed this project without his supportive and collaborative spirit. During times when I doubted my own abilities, he remained positive and confident in what I could accomplish. Furthermore, he continues to challenge me to expect great things from myself and be the best at what I do. His generosity and enthusiasm as a mentor are unparalleled and have shaped me into a confident academic psychologist, and for that I am deeply grateful.

Thank you to William Matthews, a member of both my master's thesis and dissertation committees, as well as my clinical supervisor. His ability to advise across both clinical and research domains has been invaluable, and he has challenged me to think about psychotherapy process in unique ways. Furthermore, he has done so with an incredible sense of humor that has made working together a true pleasure. Also, thank you to my committee members Lisa Harvey and Ronnie Janoff-Bulman for their enthusiasm and ever-thoughtful insights about the project.

I am also indebted to Henny Westra and Mariyam Ahmed for providing the initial inspiration for this study and for their willingness to share their wisdom throughout the project.

I would also like to acknowledge my fellow lab members, Samantha Bernecker and Nicholas Morrison. Weekly lab meetings have been wonderfully supportive and collaborative with plenty of laughter too. Nick showed a particular enthusiasm about this 
project and played an instrumental role in the implementation of the study for which I am very thankful.

Over the past two years, many research assistants have assisted with this project. I would especially like to thank Tessa Nalven and Felicia Romano for their hard work and dedication. They gracefully balanced their own busy schedules with the demanding responsibilities of the work. I am still astounded by their eagerness to do more than what was expected for my benefit and that of the project. I am also indebted to the following research assistants for their contribution the study: Kaitlin Banschback, Christina Colman, Elizabeth du Toit, Terence Howard, Emily Luukko, Haruna Matsusaka, Erin McVicar, Kathryn Rosoff, Kaitlin Silkowitz, Brittany Stepton, and Lucia Viegas-Barros. Additionally, it is important to thank the Society for Psychotherapy Research, the Society for the Exploration of Psychotherapy Integration, and the Graduate School of the University of Massachusetts Amherst for funding this project. It is humbling to know that these organizations see the importance of this work broadly and believed in the value of this project in particular.

Many friends and extended family members have been with me throughout this process as well. There are too many to list here, but know that I have a profound appreciation for all that you have done to support me through the dissertation process and beyond. You have given me the confidence and strength to succeed.

Finally, I have deep gratitude to my parents for the unconditional love and support they have given as I have pursued my goals. As psychologists themselves, they have also provided the greatest inspiration for me to embark on this career path. In particular, I want to thank my dad who could not be here to see the completion of this project and my 
graduate degree, but who was extremely proud of my accomplishments and always celebrated my successes to the fullest. This project is one testament to their unwavering support throughout my life. 


\begin{abstract}
THE INFLUENCE OF EXPECTANCY PERSUASION TECHNIQUES ON SOCIALLY ANXIOUS ANALOGUE PATIENTS' TREATMENT BELIEFS AND THERAPEUTIC ACTIONS
\end{abstract}

SEPTEMBER 2015

REBECCA M. AMETRANO, B.A., UNIVERSITY OF MICHIGAN

M.S., UNIVERSITY OF MASSACHUSETTS AMHERST

Ph.D., UNIVERSITY OF MASSACHUSETTS AMHERST

Directed by: Professor Michael J. Constantino

Although patients' psychotherapy outcome expectations correlate with

posttreatment outcome, there is limited research explicating treatment elements that causally influence these expectations. Most relevant studies have focused on varied deliveries of a treatment rationale. Although elements of rationale delivery appear important for altering patients' expectations, many studies have been marked by methodological shortcomings, such as lack of a control group. In this clinical analogue experiment, I examined the influence of expectancy persuasion methods, delivered in a video-based presentation of a cognitive-behavioral treatment rationale for social anxiety, on analogue patients' post-rationale treatment beliefs, treatment motivation, social anxiety symptoms, and therapeutic action. One hundred and seventy-eight undergraduates screened for elevated social anxiety, and matched for sex and treatment history, were randomized to the experimental (rationale plus expectancy persuasion video) or comparison (rationale only video) group. Consistent with my hypotheses, there were significant increases across both groups in anxiety change expectations, perceived 
confidence in using CBT exposure techniques to address social anxiety, and perceived helpfulness of exposure techniques. Counter to my predictions, no other effects of time, group, or their interaction emerged for the various dependent variables. Additionally, exploration of socioeconomic status, conceptualization of social anxiety, and initial anxiety change expectations as potential moderators of group effects on the dependent variables revealed no significant findings. The results underscore the clinical importance of delivering a clear treatment rationale; however, they also suggest that the specific methods for persuading patients' treatment beliefs and activities may have lacked sufficient potency to augment the effects of general rationale delivery. 


\section{TABLE OF CONTENTS}

Page

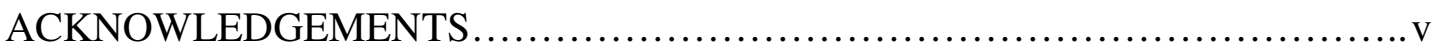

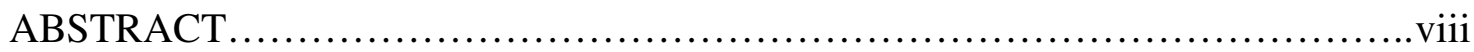

LIST OF TABLES...........................................................

\section{CHAPTER}

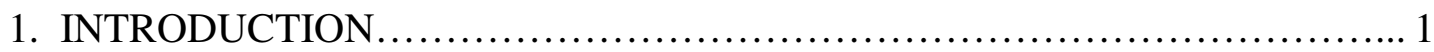

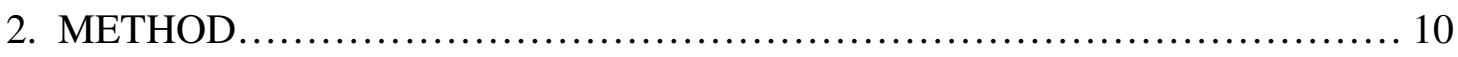

Overview..................................................... 10

Participants.................................................... 10

Rationale Videos.................................................... 11

Prescreen Measures..................................................12

Primary Dependent Variable Measures............................... 13

Secondary Dependent Variable Measures............................. 14

Baseline Covariates............................................. 17

Baseline Moderator Measures.........................................19

Baseline Matching Variable Measures................................. 19

Manipulation Check............................................... 20

Procedure........................................................ 21

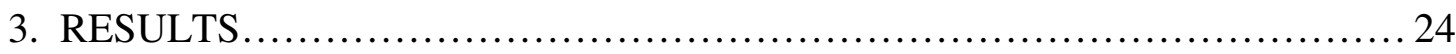

Preliminary Analyses............................................24

Manipulation Check Analyses..................................... 26

Primary Analyses................................................. 27

Secondary Analyses........................................... 28

Ancillary Analyses............................................. 30

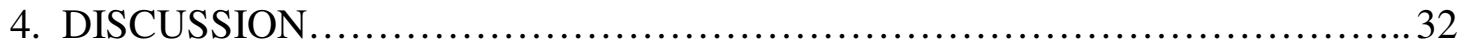

\section{APPENDICES}

A. EXPERIMENTAL VIDEO SCRIPT.............................5 54

B. COMPARISON VIDEO SCRIPT ..............................60

C. FEAR OF NEGATIVE EVALUATION SCALE - BRIEF...............66 
D. ANXIETY CHANGE EXPECTANCY SCALE.

E. PERCEIVED EXPOSURE CONFIDENCE/HELPFULNESS

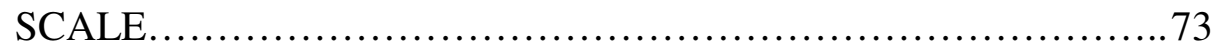

F. ADAPTED CREDIBILITY \& EXPECTANCY

QUESTIONNAIRE ........................................... 74

G. COUNSELOR RATING FORM - SHORT VERSION ...................76

H. BELIEFS ABOUT PSYCHOLOGICAL SERVICES SCALE.............78

I. INTERPERSONAL EXPOSURE FREQUENCY SCALE .................80

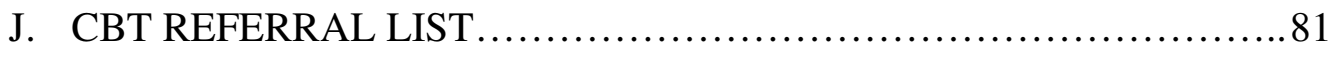

K. CLIENT MOTIVATION FOR THERAPY SCALE......................82

L. BRIEF SYMPTOM INVENTORY ................................ 83

M. POSITIVE AND NEGATIVE AFFECT SCHEDULE.................... 86

N. UNIVERSITY OF RHODE ISLAND CHANGE ASSESSMENT -

ACTION SUBSCALE................................................ 87

O. DEMOGRAPHIC QUESTIONNAIRE ................................. 89

P. CONCEPTUALIZATION OF SOCIAL ANXIETY .....................91

Q. PSYCHOTHERAPY HISTORY .................................. 92

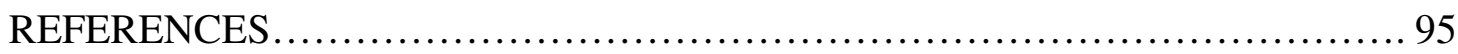




\section{LIST OF TABLES}

Table

1. Descriptive Statistics for Participants' Sociodemographic Variables

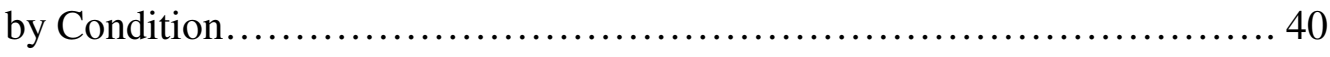

2. Descriptive Statistics for Participants' Past Treatment History

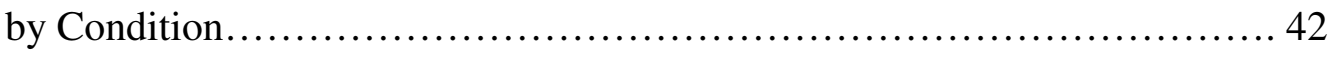

3. Descriptive Statistics for Dependent Variables by Condition................... 43

4. Percent of Participants Missing Data by Questionnaire......................... 45

5. Intercorrelations for Dependent Variables at Time $1 \ldots \ldots \ldots \ldots \ldots \ldots \ldots \ldots \ldots \ldots$

6. Intercorrelations for Proposed Covariates and Dependent Variables.............. 48

7. ANCOVA Results for Time (Within Subjects), Condition

(Between Subjects), and their Interaction..............................49

8. Logistic Regression Results Predicting Requests for CBT Referrals..............51

9. ANCOVA Results for Moderation Analyses.................................52

10. Hierarchical regressions predicting exposure frequency at

2-week follow-up............................................. 53 


\section{CHAPTER 1}

\section{INTRODUCTION}

Patients' expectations for a treatment's effectiveness, or outcome expectations, have long been considered important pantheoretical and pandiagnostic factors in psychotherapy (e.g., Constantino, 2012; Frank, 1961; Goldfried, 1980). Box count (Arnkoff, Glass, \& Shapiro, 2002) and narrative (Greenberg, Constantino, \& Bruce, 2006) reviews have pointed to outcome expectations having a somewhat mixed association with treatment outcomes, although with more studies demonstrating a correlation between higher outcome expectations and favorable treatment outcomes than an inverse or null association. Further, in a meta-analysis of 8,016 patients across 46 independent samples, there was a small but significant correlation between higher expectations of a treatment's utility and posttreatment symptom reduction (weighted $r=$ $.12, p<.001, C_{.95} .10$ to .15; Constantino, Glass, Arnkoff, Ametrano, \& Smith, 2011).

Despite the correlation between patients' prognostic outcome expectations and their posttreatment outcome, little research has identified treatment elements that causally influence these expectations. Some early studies highlighted the potential value of implementing preparatory interventions for influencing patients' treatment beliefs broadly speaking; however, such work did not specifically elucidate which methods were responsible for changes in these beliefs. For example, Hoehn-Saric and colleagues (1964) developed a pretreatment role-induction interview (RII) to teach patients appropriate expectations about therapy in the service of fostering adaptive treatment process and outcome. Their RII had four components targeting various beliefs and expectation types: (a) a general description of psychotherapy (i.e., broad socialization), (b) a description of 
the patient and therapist's expected behavior (i.e., role expectations), (c) preparation for some typical phenomena that were likely to occur during therapy (e.g., resistance) (i.e., process expectations), and (d) suggestion that the treatment would be effectual within four months (i.e., outcome expectations). The results showed that individuals receiving the pre-treatment RII, relative to those who did not, attended treatment more frequently and had significantly better treatment outcome. Although the results suggested that the RII was generally beneficial, the authors did not assess the specific effects of its four components on patients' beliefs and expectations, and they did not assess if changes in such beliefs were responsible for variability in the treatment processes and outcomes assessed. Moreover, only the fourth component of the RII focused explicitly on outcome expectations; thus, the findings, while promising, provided little insight into specific causal influences on patients' prognostic outcome expectations.

In a later study, cocaine users receiving motivational enhancement therapy (MET) prior to a course of cognitive behavioral therapy (CBT) attended more sessions, reported a stronger desire for abstinence, and endorsed higher treatment outcome expectations than those participants who did not receive MET (McKee et al., 2007). MET involved motivational interviewing (MI; Miller \& Rollnick, 1992; Miller, Zweben, DiClemente, \& Rychtarik, 1992) techniques to increase patients' commitment to change. Given that MI does not focus explicitly on enhancing outcome expectations, the results, while promising in revealing an effect on process, outcome, and beliefs, did not clarify specific expectancy persuasion strategies that might causally increase patients' outcome expectations. 
There is, though, a small body of preliminary research that has directly tested whether explicit therapist persuasion strategies foster adaptive treatment beliefs like outcome expectancies (for a comprehensive review see Constantino, Ametrano, \& Greenberg, 2012). For example, Kazdin and Krouse (1983) examined, in a series of analogue studies with unselected undergraduates, whether altering the delivery of a psychotherapy treatment rationale would influence participants' expectations. They found, using audiocassette recordings that described clinical case material and a corresponding treatment approach, that when therapy descriptions were more "prestigious" (i.e., noting that the treatment was based on scientific research, tested in clinical trials worldwide, and novel in comparison to other therapies), included vignettes of successful cases, incorporated technical jargon, or were said to have a broad focus on affect, cognition, and behavior, they garnered higher expectations for therapeutic change than when the descriptions excluded these elements. Thus, it is possible that variations on the presentation of a treatment rationale directly influence the listener's prognostic beliefs about treatment. Several limitations, though, characterized this work. For example, the clinical material was presented to an unselected sample; thus, the material described may have been salient for some participants, while having little to no relevance for others. Moreover, with the material delivered in audio-recorded vignettes about other patienttherapist dyads, there was a rather compromised analogy to a personal clinical setting in which an individual would hear a specific treatment rationale from a visible psychotherapist about a problem of direct relevance to him or her.

Horvath (1990) attempted to replicate and extend Kazdin and Krouse's (1983) work through an analogue study in which audiocassette-recorded treatment rationales 
were varied by therapeutic focus (behavioral only versus broad a la Kazdin and Krouse), number of techniques presented (few versus many), and length (i.e., number of words in the rationale) in order to examine the effects of these variables on participants' treatment outcome expectations. Results indicated that moderate length rationales (approximately 250-word descriptions) contributed most to raising expectations. Horvath suggested that a moderate length rationale might be influential because it is clear and easy to understand, while remaining long enough to be compelling and persuasive. This interpretation is consistent with the broader persuasion literature, which suggests that people are less likely to be persuaded by material if it is difficult to understand (Chaiken \& Eagly, 1976). Horvath's study, though, was marked by the same limitations as Kazdin and Krouse's study described above. Further, the rationales in both studies were extremely brief (less than 400 words each), which also limits generalizability to real-world clinical exchanges in which a therapist often spends substantial time reviewing the rationale underlying a given treatment.

Several other studies have also supported the influence of elements of rationale presentation on participants' outcome expectations. Rosen (1975) conducted an analogue study in which undergraduate students rated their fear of snakes and then received a description of systematic desensitization with the addition of positive expectancy instructions (in which participants were led to believe that fear reduction was likely), negative expectancy instructions (in which participants were led to believe that fear reduction was unlikely), or no expectancy instructions. Varying the therapeutic rationales with different expectancy instructions influenced patients' expectations about the treatment's effectiveness; participants who received the positive expectancy instructions 
reported having more positive expectations than those who received the negative expectancy instructions. Another analogue experiment examined the effects of brief treatment rationales for different therapy types (i.e., psychoanalytic, rationale-emotive therapy, behavior therapy) on participants' treatment beliefs; there was also a no rationale control condition (Wollersheim, Brodewick, Knapp, McLellarn, \& Paul, 1982). Participants in the behavior therapy and the no rationale control condition reported more confidence in treatment success than participants in the rationale-emotive therapy condition. These studies had similar limitations to the Kazdin and Krouse (1983) and Horvath (1990) studies; that is, unselected samples, compromised personal clinical analogy, and, in the case of Wollersheim et al., very brief rationales.

In a more recent analogue study with a selected (for elevated social anxiety) undergraduate sample, Ahmed and Westra (2009) examined whether simply providing a systematic rationale of CBT for social anxiety would increase participants' expectations for therapeutic change from pre- to post-rationale presentation. Results showed that participants' expectations for being able to manage their anxiety increased post-rationale. Moreover, positive response to the treatment rationale was associated with participants taking CBT-consistent therapeutic action (i.e., self-generated exposures to anxietyprovoking interpersonal situations) by a follow-up assessment; that is, greater postrationale exposure confidence and perceived helpfulness of exposure exercises were related to more interpersonal exposures by 1-month follow-up. These results further support the notion that treatment rationales may influence patients' outcome expectations. They also suggest that response to a rationale may influence treatmentconsistent behavior. Although this study had several virtues (e.g., selected sample, 
follow-up assessment of therapeutic action), it also lacked a comparison group, which made it impossible to rule out other explanations for pre- to post-rationale expectancy change, such as social desirability or experimental demand characteristics.

The studies reviewed above collectively suggest the potential clinical importance of treatment rationales, and varied elements of them, for altering treatment beliefs. Given that rationales are typically intended to (a) help people develop an understanding of their problems, which may have been previously unnamed, (b) present a potential method for reducing or eliminating their problems, and (c) educate them about the utility of the particular treatment, it appears likely that they help foster a sense of remoralization-a state most prominently reflected in heightened expectation for adaptive change (Frank, 1961; Frank \& Frank, 1991). Yet, despite the apparent clinical relevance of individuals' treatment beliefs, expectations have largely remained an undervalued psychotherapy variable both clinically and conceptually (Constantino \& Westra, 2012; Weinberger \& Eig, 1999). Such undervaluing may partially be a function of the relatively small research base that, to date, has been marked with several methodological shortcomings. Thus, with the present study, I attempted to replicate and extend aspects of the most rigorous prior research (i.e., Ahmed \& Westra, 2009; Horvath, 1990; Kazdin \& Krouse, 1983) by addressing some of those methodological limitations.

Specifically, I conducted an analogue experiment to examine the influence of specific expectancy persuasion methods, culled from the extant empirical literature and delivered in the context of a video-based presentation of a CBT rationale for social anxiety, primarily on (a) anxiety change expectations, (b) perceived confidence in conducting CBT exposure techniques to address social anxiety, and (c) perceived 
helpfulness of exposure techniques. This study focused on these three primary variables in order to replicate the work of Ahmed and Westra (2009). I secondarily examined the influence of expectancy persuasion methods on other potentially related treatment beliefs (i.e., general psychotherapy outcome expectations, perceived treatment credibility, perceived therapist expertness, and attitudes toward seeking psychological help), CBTspecific therapeutic actions and general therapeutic actions taken by a follow-up period, motivation for treatment, and social anxiety. A selected sample of undergraduate participants with elevated social anxiety was randomly assigned to the expectancyaugmented rationale condition or to a comparison condition that included the same presentation of the treatment rationale without the expectancy elements. This study focused on a CBT rationale for social anxiety in order to replicate Ahmed and Westra's work and because elevated social anxiety is common among college students. Reflected in the summary above are several key strengths to the present analogue design, which offer improvements over the collective extant literature. These include: (a) a comparison group to allow for testing the causal specificity of the expectancy persuasion methods, (b) a selected sample, which ensures that the clinical material delivered in the context of the treatment rationale has high salience for the participants, (c) a video presentation of the rationale, which allows for virtual exposure to a psychotherapist and contributes to a more clinically analogous context, and (d) lengthier rationales (over 3,000 words and approximately $20 \mathrm{~min}$ in length), which more closely approximates clinical reality.

I expected that across groups there would be an increase in participants' (a) specific expectations for being able to change their anxiety, (b) perceived confidence in conducting CBT exposure techniques to address social anxiety, and (c) perceived 
helpfulness of exposure techniques from pre- to post-rationale presentation (time 1 to time 2), which would replicate Ahmed and Westra's (2009) findings. As an extension of their work, I examined those same variables across three time points (including a longerterm follow up); I hypothesized that participants in the expectancy persuasion group, relative to those in the comparison group, would report more adaptive changes in those variables across the three time points. Secondarily, I also expected that individuals in the expectancy persuasion group, relative to those in the comparison group, would evidence more adaptive changes across the three time points on other related treatment beliefs, treatment motivation, and social anxiety. I also predicted that experimental group participants would report more specific and general therapeutic actions taken by the follow-up period relative to comparison group participants.

I also explored socioeconomic status (SES), conceptualization of social anxiety, and initial level of anxiety change expectations as potential moderators of the impact of rationale condition on the three primary dependent variables. I explored these variables as potential moderators for multiple reasons. First, it is possible that lower SES participants may derive a greater benefit from the expectancy persuasion strategies than higher SES participants because they may have had less exposure to psychotherapy in person or through various media types. Thus, they may be more open to influence and gain the most new knowledge from the video, which may in turn promote more favorable changes in the dependent variables (relative to higher SES participants who may have been more familiar with psychotherapy in general and possibly CBT in particular, thus rendering the expectancy persuasion strategies less necessary). Second, given the video's focus on a psychosocial approach to treating social anxiety, it is plausible that the expectancy 
persuasion strategies may have an impact only for those participants who conceptualize their social anxiety as being related to psychological causes (e.g., emotions, thoughts, and interpersonal factors), as opposed to more biological or situational causes. Lastly, presenting levels of anxiety change expectations may emerge as a specific condition under which the expectancy persuasion techniques will be effective. Specifically, participants with an initially low level of anxiety change expectations may have more room to benefit from the expectancy persuasion techniques than those individuals with initially high expectations. 


\section{CHAPTER 2}

\section{METHOD}

\section{$\underline{\text { Overview }}$}

Data were collected over the course of three academic semesters (Spring 2013, Fall 2014, Spring 2014). Eligible participants were undergraduates at the University of Massachusetts Amherst identified through the Psychology Department prescreening protocol. Inclusion criteria required: (a) scoring above a clinical cutoff for elevated social anxiety, and (b) endorsing a subjective sense of struggling with social anxiety (to confirm that participants believed that social anxiety was personally relevant). The measures for these two inclusion domains are described below.

To determine sample size, I conducted a power analysis for an analysis of covariance (ANCOVA) with main effects, interactions, and covariates. This analysis revealed a required sample size of 171 to detect a medium effect with power of .90 and an alpha of .05 .

\section{$\underline{\text { Participants }}$}

Participants were the 178 undergraduates who completed the three study sessions (5 participants withdrew before completing all sessions). The average age of the sample was 19.75 years $(S D=1.69$ years). Participants were primarily female $(90 \%)$, White (77\%), and single (80\%). Descriptive statistics for participant sociodemographic variables are presented in Table 1 by rationale condition. Sixteen percent of participants were currently in psychotherapy for any psychological difficulties, $9.5 \%$ were currently in psychotherapy for social anxiety concerns, $47 \%$ had previously been to therapy for any psychological difficulties, and $28 \%$ had previously been to therapy for social anxiety concerns. Descriptive statistics for participants' psychotherapy history are presented in 
Table 2 by rationale condition. There were no significant between rationale condition differences on any sociodemographic or psychotherapy history variables.

\section{$\underline{\text { Rationale Videos }}$}

Two professionally recorded videos (each approximately 20 min long) form the basis of the experimental manipulation. Across both videos, the same clinician (a White male therapist who is an experienced clinical psychologist) delivers the CBT for social anxiety rationale. CBT is presented as an empirically supported treatment for this disorder, and the clinician reviews both basic information about social anxiety (e.g., central nature of the problem, common triggers, avoidance as a primary consequence) and the central elements of CBT (e.g., exposure to anxiety-provoking stimuli in the service of disrupting avoidance and promoting habituation).

In the expectancy-augmented video (i.e., the experimental condition), the therapist interjects into the CBT treatment rationale various expectancy persuasion techniques that were culled from the small empirical literature on expectancy persuasion (see Constantino et al., 2012 for a full review; see also Ahmed \& Westra, 2009; Kazdin $\&$ Krouse, 1983). These evidence-based methods (albeit limited evidence) include providing hope-inspiring statements, highlighting empirical support for CBT for social anxiety, socializing the patient to the treatment process, using technical jargon, and discussing the broad effects of the treatment (see Appendix A for the experimental video script).

The comparison condition video includes presentation of the CBT rationale only. To control for video length, the clinician provides additional examples of CBT and multiple interim summaries of the information provided. In this video, the clinician 
refrains from presenting any of the explicit expectancy persuasion techniques included in the expectancy video (see Appendix B for the comparison video script).

\section{$\underline{\text { Prescreen Measures }}$}

To assess for elevated social anxiety, potential participants completed, as part of the prescreening protocol, the Fear of Negative Evaluation-Brief Form (FNEB; Leary, 1983; see Appendix C), a 12-item measure of social-evaluative anxiety. Each FNEB item is rated on a scale from 1 ("Not at all characteristic of me") to 5 ("Extremely characteristic of me") with a possible total score range of 5 to 60 . To be study eligible, and consistent with Ahmed and Westra (2009), participants needed to score at least one standard deviation above the mean of a non-clinical normative sample (i.e., above 43.8; Leary, 1983). The FNEB is highly correlated with its original version (Collins, Westra, Dozois, \& Stewart, 2005; Leary, 1983), and it has demonstrated high test-retest reliability $(r=.94)$. Cronbach's alpha for the current study ranged from .86 to .90 . The FNEB also correlates significantly with social avoidance (Collins et al., 2005).

As a confirmation of the personal relevance of social anxiety, participants responded "yes" or "no" to the following item: "Some people struggle with social anxiety, which is a fear of being in or thinking about social situations (e.g., interacting with other people, giving a speech, being in large crowds, etc.). Do you believe that you have any concerns about or struggles with social anxiety?" As noted previously, a "yes" response was required for inclusion. Over the course of the three semesters, 4,646 individuals took the prescreening questionnaire and 844 (18\%) met the inclusion criteria. 


\section{$\underline{\text { Primary Dependent Variable Measures }}$}

Expectations for anxiety change. To assess anxiety change expectations, participants completed the Anxiety Change Expectancy Scale (ACES; Dozois \& Westra, 2005; see Appendix D). The ACES includes 20 items rated on a scale from 1 ("Strongly disagree") to 5 ("Strongly agree"); thus, the total score range is 20 to 100 . The ACES demonstrated high internal consistency in the current study ( $\alpha$ s ranging from .90 to .94), and has shown good convergent and divergent validity (Dozois \& Westra, 2005).

Perceived confidence and helpfulness in conducting exposure techniques/helpfulness of treatment procedures. Participants' reactions to the central CBT procedure discussed in the videos (i.e., interpersonal exposure) were measured with the Perceived Exposure Confidence/Helpfulness Scale (PECHS; Ahmed \& Westra, 2009; see Appendix E). The scale requires participants to first identify three social/public situations that they tend to avoid or endure with high anxiety. They are then asked to rate, on a scale from 1 ("Not at all confident) to 100 ("Extremely confident"), their perceived confidence in conducting exposure techniques related to each of the situations they identified (i.e., they give a separate rating for each situation). These ratings constitute the "confidence" variable. Next, they are asked to rate, on a scale from 1 ("Not at all helpful") to 100 ("Extremely helpful"), the perceived helpfulness of deliberate exposure to each of the situations they identified. These ratings constitute the "helpfulness" variable. There are two versions of the measure, one for pre-rationale presentation and one for post-rationale presentation. The post-rationale version differs in that it consists of abbreviated directions and it pre-populates the three anxiety-provoking situations that the participant indicated 
in the pre-rationale version (to ensure that they are rating the same situations from pre to post).

\section{$\underline{\text { Secondary Dependent Variable Measures }}$}

General psychotherapy outcome expectations. To assess general psychotherapy outcome expectations, participants completed the expectancy item of the Credibility/Expectancy Questionnaire (CEQ; Devilly \& Borkovec, 2000; see Appendix F). The CEQ expectancy item is rated on an 11-point scale (from 0\% to $100 \%$ expected improvement in 10-point intervals) and has been used as a measure of outcome expectancy on its own (e.g., Borkovec, Newman, Pincus, \& Lytle, 2002; Vogel, Hansen, Stiles, \& Gotestam, 2006), possesses good face validity, and has been shown to predict treatment outcome (e.g., Borkovec et al., 2002; Price, Anderson, Henrich, \& Rothbaum, 2008).

Perceived treatment and clinician credibility. To assess perceived treatment and clinician credibility, participants completed the CEQ credibility scale (see Appendix F) and the Counselor Rating Form-Short Version (CRF-S; Corrigan \& Schmidt, 1983; see Appendix G), respectively. The CEQ credibility scale is derived from patients' summed responses to three cognitively-based items assessing how logical the therapy seems, how successful they think the treatment will be in reducing symptoms, and how confident they would be in recommending the treatment to a friend with similar problems. Each credibility item is rated on a 9-point scale (1 "Not at all logical/useful/confident" to 9 "Very logical/useful/confident"), rendering a theoretical scale range of 3 to 27 . The CEQ

credibility scale showed high internal consistency in the current study $(\alpha=.82)$, strong 
item-factor loadings (ranging from .62 to .78 across two studies), and good test-retest reliability ( $r=.75$ in one study) (Devilly \& Borkovec, 2000).

The CRF-S is a 12-item measure assessing client-perceived therapist expertness, attractiveness, and trustworthiness ( 4 items per subscale). Each item is rated on a 7-point Likert scale ranging from 1 ("Not very") to 7 ("Very"). Subscale scores on each of the three domains can range from 4 to 28 . Total scores can range from 12 to 84 . The CRF-S is highly correlated with the original scale (Corrigan \& Schmidt, 1983; Epperson \& Pecnik, 1985). Further, the measure demonstrated high internal consistency in the current study ( $\alpha=.92$ ), and the three factors have been supported through confirmatory factor analysis (Ponterrotto \& Furlong, 1985).

Attitudes toward seeking psychological help. Attitudes toward seeking psychological help were assessed with the Beliefs About Psychological Services Scale (BAPS; Ægisdottir \& Gerstein, 2009; see Appendix H). The BAPS includes 18 items, each of which is rated on a 6-point scale ranging from 1 ("Strongly disagree") to 6 ("Strongly agree"). The scale contains three subscales including "Intent," which measures a person's willingness to seek psychological services, "Stigma Tolerance," which measures a person's negative beliefs about psychotherapy, and "Expertness," which measures a person's beliefs about psychotherapists' knowledge about the unique characteristics of psychotherapy. The Intent subscale includes six items and has a total score range of 6 to 36, the Stigma Tolerance subscale includes eight items with a total score range of 8 to 48 , and the Expertness subscale has four items with a total score range of 4 to 24 . Higher scores on all three subscales indicate a more positive attitude (i.e., high likelihood of seeking services if needed, low stigma related to seeking psychological 
services, and belief that psychologists are knowledgeable and helpful to those suffering from psychological difficulties). The BAPS total score showed high internal consistency in this study ( $\alpha$ s ranging from .87 to .89 ).

Specific therapeutic actions. To assess CBT-specific therapeutic actions (i.e., selfgenerated interpersonal exposures), participants completed the Interpersonal Exposure Frequency Scale (Ahmed \& Westra, 2009; see Appendix I). Ahmed and Westra developed this scale to assess the frequency with which subjects exposed themselves to interpersonal situations following the presentation of a treatment rationale. Participants are presented with the same three anxiety-provoking situations that they indicated on the

\section{Perceived Exposure}

Confidence/Helpfulness Scale (discussed previously) and asked to rate on a scale from 1 ("Not at all") to 10 ("Very often") how often they put themselves in these anxietyprovoking situations in the service of eventually reducing their anxiety. The three items are then summed to create a total score (range of 3 to 30), with higher scores indicating more exposure frequency.

General therapeutic actions. Participants completed the following study-specific item that assessed their general treatment-seeking behavior: "Since participating in the second session of this study approximately two weeks ago, to what degree have you taken any actions toward seeking therapy?" The responses include: 0 ("No actions taken"), 1 ("Looked up information on the Internet [or elsewhere] related to seeking therapy"), 2 ("Called one or more places to see if they are taking new clients"), 3 ("Made an appointment for therapy"), and 4 (“Attended one or more therapy sessions”). Thus, 
higher scores indicate progressively more intense actions toward seeking psychotherapy were taken.

To further assess therapeutic action, participants responded (yes/no) post-rationale to whether they would like to receive a referral list of local clinicians who provide CBT (see Appendix J).

Motivation for future engagement in psychotherapy. To assess motivation for future psychotherapy engagement, participants completed the 4-item Intrinsic Motivation subscale of the Client Motivation for Therapy Scale (CMOTS; Pelletier, Tuson, \& Haddad, 1997; see Appendix K). Each item rated is on a 7-point Likert scale ranging from 1 ("Does not correspond at all") to 7 ("Corresponds exactly"), yielding a score range of 4 to 28 (higher scores reflect higher levels of motivation). The complete scale measures six types of motivation that underlie Deci and Ryan's (1985) Self Determination Theory, including amotivation, external regulation, introjected regulation, identified regulation, integrated regulation, and intrinsic motivation. Again, only the intrinsic motivation was used in the present study. Pelletier et al. (1997) found that the scale possesses good convergent and divergent validity and good factor structure. The measure showed good internal consistency in this study ( $\alpha$ s ranging from .82 to .86 ).

Social anxiety. Social anxiety was measured with the FNEB (described previously).

\section{$\underline{\text { Baseline Covariates }}$}

The three covariates determined a priori are described below. Other variables that were significantly correlated with a dependent variable at time 1 were added as covariates in the corresponding primary statistical models (see results section below). 
General distress. To assess for general presenting distress, participants completed the Brief Symptom Inventory (BSI; Derogatis \& Melisaratos, 1983; see Appendix L), a 53-item measure of global psychopathology. The 5-point scale ranges from 0 ("Not at all") to 4 ("Extremely"), with higher scores reflecting more psychiatric distress (possible range of 0 to 212). The BSI possesses excellent convergent and construct validity (Derogatis \& Melisaratos, 1983). The measure showed high internal consistency in this study $(\alpha=.97)$.

General mood state. To assess for general mood state, participants completed the Positive and Negative Affect Scale (PANAS; Watson, Clark, \& Tellegen, 1988; see Appendix M). The PANAS includes two 10-item mood scales, one of which measures positive affect (PA) and the other negative affect (NA). The items are on a 5-point Likert scale ranging from 1 ("Very slightly or not at all") to 5 ("Extremely"). Higher scores on the PA scale indicate more positive affect (possible range of 1 to 50) and higher scores on the NA scale indicate more negative affect (possible range of 1 to 50). The measure possesses strong convergent and discriminant validity (Watson et al., 1988), and showed high internal consistency in this study ( $\alpha$ s ranging from .88 to .90 for both PA and NA).

Stages of change. To assess readiness for psychotherapeutic change, participants completed the Action subscale of the University of Rhode Island Change Assessment scale (URICA; McConnaughy, Prochaska, \& Velicer, 1983; see Appendix N). The URICA is a 32-item scale that assesses readiness for change based on the five stages of change outlined by DiClemente and Prochaska (1982). Each item is rated on a 5-point Likert scale ranging from 1 ("Strongly disagree") to 5 ("Strongly agree"). The Action subscale includes eight items that assess whether the individual is taking action toward 
fixing his or her problem; the score range is from 8 to 40 , with higher scores indicating more readiness to take action. The scale showed high internal consistency in the current study ( $\alpha$ s ranging from .89 to .90$)$.

\section{$\underline{\text { Baseline Moderator Measures }}$}

Socioeconomic status. To examine socioeconomic status (SES), participants completed a demographic questionnaire that includes a SES item (i.e., annual family household income; see Appendix O). The item has nine options ranging from 1 (" $\$ 25,000$ or less") to 9 ("\$200,001 or more") and was used as an ordinal variable.

Conceptualization of social anxiety. To examine conceptualization of social anxiety, participants completed a study-specific measure assessing the degree to which they believe that their social anxiety is related to psychological versus biological causes (see Appendix P). Each item is rated on a 7-point Likert scale ranging from 1 ("Strongly disagree") to 7 ("Strongly agree"). The measure has four items, three of which relate to psychological factors (i.e., interpersonal factors, thoughts and beliefs, and emotions) and one of which relates to biological factors; the score range is from 4 to 28 , with higher scores indicating a more psychological conceptualization and lower scores indicating a more biological conceptualization.

Initial anxiety change expectations. Participants' ratings on the ACES (described previously) were used to examine initial anxiety change expectations as a potential moderator of the treatment rationale condition.

$\underline{\text { Baseline Matching Variable Measures }}$ 
Participants were matched on sex (demographic questionnaire) and prior treatment history (see prior history questionnaire in Appendix Q) in the randomization protocol.

\section{Manipulation Check}

To ensure that participants experienced the video manipulation as intended, they completed an idiosyncratic measure assessing three domains. First, general comprehension of the video content was assessed with the following yes/no questions: (1) "The therapist in the video discussed a condition called paranoid schizophrenia" (no), (2) "The therapist in the video discussed a condition called social anxiety or social phobia" (yes), and (3) "The content of the video centered primarily around taking pills in order to reduce symptoms" (no). All three of these questions had to be answered correctly in order for the participant's data to be included in the final analyses.

Next, recollection of components of the CBT rationale was assessed with the following yes/no questions: (1) "The therapist discussed the importance of exposure to anxiety provoking stimuli" (yes), (2) “The therapist said that avoidance makes anxiety better" (no), and (3) "The therapist mentioned that research has shown CBT is effective for treating social anxiety" (yes).

Lastly, recollection of components of the expectancy persuasion techniques were assessed using the following yes/no questions: (1) "The therapist specifically noted that over his 30 years of clinical practice he has enjoyed working with people who suffer from social anxiety because they often respond to treatment and their prognosis for changing their anxiety is very good" (yes - for the experimental group), (2a) For the first 43 participants: "The therapist discussed how CBT is more than just immediately helpful for 
social anxiety; he made it a point to say that the positive effects of CBT are durable, which means the effects are long lasting." (yes - for the experimental group), (2b) For the remaining 135 participants: "The therapist discussed a method for rating your level of anxiety called "Subjective Units of Distress" or SUDS" (yes - for the experimental group $)^{1}$, and (3) "The therapist mentioned that CBT usually lasts around 20 sessions, but could be longer or shorter depending on the patient, and that "homework" assignments are often a part of treatment" (yes - for the experimental group).

We expected the two groups would be roughly equivalent in what they remembered on the items testing recollection of the general components of the CBT rationale. However, we expected the two groups to be statistically different on the items testing recollection of the expectancy persuasion techniques, with the experimental group endorsing these items more than the comparison group.

\section{Procedure}

Potential participants completed the Psychology Department prescreening questionnaire, including the study-relevant prescreen items reviewed earlier, through a web-based human subjects system. Those meeting inclusion criteria were contacted by a research assistant and invited to participate in this study. The study involved three individual lab sessions.

During the first session, participants completed the FNEB, demographic questionnaire, social anxiety conceptualization measure, BSI, PANAS, URICA,

\footnotetext{
${ }^{1}$ Following a first wave of data collection with 43 participants it became clear that item 2 a was poorly worded and did not differentiate the groups effectively. Thus, the item was replaced with version $2 b$, and the replacement differentiated the groups. See the "Manipulation Check Analyses" section for the results.
} 
psychotherapy history questionnaire, CEQ expectancy item, ACES, PECHS, and BAPS (measures were presented in a random order at all time points to control for order effects). Participants, matched on sex and prior psychotherapy experience, were then randomly assigned to the experimental or comparison condition.

Approximately five days later $(M=5.48$ days, $S D=2.05$ days $)$, participants returned for the second lab session during which they first watched their assigned video and then completed the CEQ credibility scale, CRF-S, manipulation check items, and all other dependent measures listed at session one (measures were again presented in a random order to control for order effects). Participants were also asked if they wanted to receive a list of cognitive-behavioral therapists before leaving the session; if they answered yes, the CBT-clinician referral list was provided. All participants also received a general mental health referral list at the conclusion of session 2 regardless of their answer to the previous question. This referral list included one no-cost and one low-cost option for therapy (this was noted on the referral list), and all research assistants were trained to tell participants, "The first two options on this list provide no-cost or low-cost services to students." This was done in order to be sure that all participants knew they could access care. The time lag between lab sessions 1 and 2 was included to lessen potential demand characteristics (i.e., that participants would assume that the experimenters expected their ratings on the primary measures to change following the video).

Approximately 14 days ( 2 weeks) later $(M=13.8$ days, $S D=2.02$ days $)$, participants returned for their third and final visit to complete the Interpersonal Exposure Frequency Scale, the study-specific measures of general and specific therapeutic actions, 
and all other dependent measures listed at session 1 (measures were again presented in a random order to control for order effects). A 2-week follow-up period was used because it was not feasible to use a longer follow-up period (as in Ahmed \& Westra, 2009). The research assistants conducting sessions 2 and 3 were unaware of the participants' assigned rationale condition in order to ensure equivalence in the treatment of all participants. 


\section{CHAPTER 3}

\section{RESULTS}

\section{$\underline{\text { Preliminary Analyses }}$}

First, I calculated descriptive statistics for all study variables, which are presented in Table 3. The average baseline FNEB score $(M=49.86, S D=7.27)$ was comparable to Ahmed and Westra's (2009) sample $(M=45.51, S D=5.08)$, and within one standard deviation of the mean for clinical samples presenting for treatment $(M=51.50, S D=$ 7.30; Collins et al., 2005), suggesting significant levels of social anxiety symptomatology. Moreover, the average baseline ACES score $(M=73.59, S D=13.65)$ was comparable to Ahmed and Westra's (2009) sample $(M=72.89, S D=12.56)$, and similar to the mean of clinically anxious samples presenting for treatment $(M=71.16, S D$ = 10.88; Westra, Dozois, \& Marcus, 2007).

For continuous variables, I examined the distributions, including kurtosis and skewness values. Descriptive statistics revealed that all continuous variables were largely normally distributed (i.e., values no higher than 2); thus, no transformations were performed. There was a small amount of missing data at the item level. Missing questionnaire items were replaced with the participant's mean item score on that measure, but only if at least $80 \%$ of the measure was complete before imputation. The percentages of missing data for each questionnaire, before and after imputation, are presented in Table 4.

Intercorrelations for all dependent variables are presented in Table 5. The CEQ expectancy item and ACES were correlated, but distinct constructs. Additionally, the PECHS confidence subscale developed by Ahmed and Westra (2009) was correlated with the ACES and the CEQ expectancy item, and the PECHS helpfulness subscale was 
correlated with the ACES. These correlations support the construct validity of the PECHS.

Next, I compared the two conditions on all dependent, control, and demographic variables; the comparisons were done to ensure group equivalence (i.e., randomization success). Independent samples $t$-tests (for continuous measures) and chi-square analyses (for categorical measures) revealed that the conditions differed significantly on none of the dependent, control, and demographic variables at time 1 . Thus, none of these variables were added as covariates in the main models. I also assessed empirically whether any demographic variables or any of the three proposed covariates (i.e., general distress, mood state, and stages of change) were significantly correlated with any of the primary or secondary dependent variables. The following psychotherapy history items were significantly correlated with several dependent variables: "Are you currently in psychotherapy for any psychological difficulties?": BAPS $(r=-.20, p<.01)$, general therapeutic actions $(r=-.57, p<.01)$; “Are you currently in psychotherapy for social anxiety concerns?": CEQ $(r=-.16, p<.05)$, general therapeutic actions $(r=-.38, p<$ $.01)$; "Have you ever been in psychotherapy for any psychological difficulties?": FNEB $(r=-.21, p<.01)$; "Have you ever been in psychotherapy for social anxiety concerns?": BAPS $(r=-.16, p<.05)$, FNEB $(r=-.19, p<.05)$. Note that two outliers were removed for the correlation analysis with the psychotherapy history item "How many times have you previously been in psychotherapy for any psychological difficulty (separate courses of treatment)" because they were more than 10 standard deviations above the mean for times previously in therapy. Additionally, one outlier was removed for the correlation analysis with the psychotherapy history item "How many times have you previously been 
in psychotherapy for social anxiety concerns (separate courses of treatment)" because it was more than 10 standard deviations above the mean for times previously in therapy for social anxiety concerns. Following removal of the outliers, neither of these psychotherapy history items was significantly correlated with any of the primary or secondary dependent variables.

Additionally, each proposed covariate was significantly correlated with several dependent variables. The BSI was significantly correlated with the ACES, PECHS (confidence and helpfulness), FNEB, general therapeutic actions, and the referral item ( $r$ s ranged from -.58 to $.39, p s<.01$ ); the PANAS (positive affect subscale) was significantly correlated with the ACES, PECHS (confidence and helpfulness), CEQ, BAPS, CMOTS, and CEQ credibility ( $r$ s ranged from .17 to $.35, p s<.05$ ); the PANAS (negative affect subscale) was significantly correlated with the ACES, FNEB, general therapeutic actions, and the referral item, ( $r$ s ranged from -.29 to $.33, p s<.05$ ); the URICA was significantly correlated with the ACES, PECHS (confidence), IEFS, CEQ, BAPS, and CMOTS ( $r$ s ranged from .17 to $.33, p s<.05)$. Intercorrelations for the proposed covariates and dependent variables are presented in Table 6. Each variable that was significantly correlated with a dependent variable at time 1 was added as a covariate in the corresponding primary model described below.

\section{Manipulation Check Analyses}

Regarding the manipulation check scales, all participants answered the three questions assessing basic comprehension of the video content correctly and, thus, no participants were removed from the primary data analyses. As intended, the two groups were perfectly equivalent on each of the three questions assessing recollection of the 
CBT content that was present in both conditions (i.e., all participants across both groups answered these three questions correctly). Also as intended, the groups differed significantly, and in the expected direction, on each of the three questions assessing recollection of the expectancy persuasion content included in the experimental condition only: item $1, \chi^{2}(1, n=178)=50.70, p<.001 ;$ item $2, \chi^{2}(1, n=135)=48.67, p<.001^{2}$; item $3, \chi^{2}(1, n=178)=64.64, p<.001$.

\section{Primary Analyses}

The primary analyses consisted of three paired $t$-tests and three mixed analyses of covariance (ANCOVA). The $t$-tests revealed significant increases, from pre- to postrationale presentation (time 1 to time 2), in anxiety change expectations, $t(178)=-2.31, p$ $=.02$, perceived confidence in conducting $\mathrm{CBT}$ exposure techniques to address social anxiety $t(176)=-7.86, p<.001$, and perceived helpfulness of exposure techniques $t(176)$ $=-6.12, p<.001$, across both groups. These findings are consistent with my predictions and the findings of Ahmed and Westra (2009). Increases in expectations about being able to change one's anxiety revealed a small effect size, $d=.11$, while increases in perceived confidence and helpfulness showed medium effect sizes, $d=.47$ and .41 , respectively (Cohen, 1988).

The ANCOVAs included time (pre- and post-rationale video and follow-up) as a within-subjects variable (i.e., slopes across 3 time points), condition (experimental or comparison video) as a between-subjects variable, and any variables that were significantly correlated with the dependent variables as the covariates. To reiterate, the

\footnotetext{
${ }^{2}$ Only 135 participants completed item 2 because, as noted, following a first wave of data collection with 43 participants, it became clear that an initial version of item 2 was poorly worded and did not differentiate the groups effectively. Thus, the item was replaced for the remaining data collection (and it is the second version of the item data analyzed here).
} 
primary dependent variables were post-rationale treatment beliefs (i.e., anxiety change expectations, perceived confidence in conducting CBT exposure techniques to address social anxiety, and perceived helpfulness of exposure techniques). The ANCOVA results are shown in Table 7. Note that sphericity could not be assumed for perceived helpfulness of CBT exposure techniques, so a Greenhouse-Geisser correction was used. Consistent with my prediction, there was a significant main effect of time on anxiety change expectations; that is, across both conditions, participants reported a significant increase in these expectations after watching a rationale video. The test of within-subject contrasts revealed that the effect was linear, $F(1,172)=4.19, p=.042$, partial $\eta^{2}=.02$.

Also consistent with my prediction, there was a significant main effect of time on perceived confidence in conducting CBT exposure techniques and perceived helpfulness of exposure techniques; that is, across both conditions, participants reported a significant increase in their perceptions after watching a rationale video. The test of within-subject contrasts for perceived confidence revealed both a significant linear, $F(1,171)=16.67, p$ $<.001$, partial $\eta^{2}=.09$, and quadratic, $F(1,171)=4.29, p=.04$, partial $\eta^{2}=.02$, effect. Descriptively, there appeared to be a steep linear increase from time 1 to time 2 and a less pronounced increase between time 2 and time 3 . The test of within-subject contrasts for perceived helpfulness revealed that the effect was linear, $F(1,172)=8.49, p=.004$, partial $\eta^{2}=.05$. Contrary to my prediction, there were no time $\mathrm{x}$ condition interactions.

\section{$\underline{\text { Secondary Analyses }}$}

Secondary analyses consisted of four mixed ANCOVAs and four one-way ANOVAs. The ANCOVAs included time (pre- and post-rationale video and follow-up) as a within-subjects variable, condition (experimental or comparison video) as a between- 
subjects variable, and any variables that were significantly correlated with the dependent variables as the covariates. To reiterate, the secondary dependent variables were: postrationale treatment beliefs (i.e., general psychotherapy outcome expectations and attitudes toward seeking psychological help), treatment motivation, and social anxiety. The ANCOVA results are shown in Table 7. Note that sphericity could not be assumed for general psychotherapy outcome expectations and treatment motivation (withinsubjects and interaction analyses only), so a Greenhouse-Geisser correction was used. Contrary to my prediction, there was not a significant main effect of time on general psychotherapy outcome expectations, attitudes toward seeking psychological help, treatment motivation, or social anxiety. Also inconsistent with my prediction, there were no time $\mathrm{x}$ condition interactions.

Given that specific therapeutic actions, general therapeutic actions, perceived treatment credibility, and perceived clinician expertness were assessed at one time point only, I conducted four one-way ANOVAs to examine the impact of condition on these variables with the appropriate covariates added. There was no effect of condition on specific therapeutic actions, $F(1,174)=.36, p=.55$, general therapeutic actions, $F(1$, $168)=.03, p=.87$, perceived treatment credibility, $F(1,175)=.31, p=.58$, or perceived clinician expertness, $F(1,175)=1.92, p=.17$.

As a final secondary analysis with a binary dependent variable (i.e., whether or not the participant requested specific CBT referrals), I conducted a logistic regression with the appropriate covariates added, and with rationale condition as the predictor and CBT referral status as the criterion $(1=$ yes, $0=$ no). The logistic regression model was statistically significant, $\chi^{2}(3)=24.59, p<.001$. The model explained $20 \%$ (Nagelkerke 
$R^{2}$ ) of the variance in referral item status and correctly classified $80.9 \%$ of cases. The Wald criterion demonstrated that rationale condition and BSI did not make significant contributions to the model, while the negative affect subscale of the PANAS did make a significant contribution to the model $(p<.01)$; individuals with higher negative affective scores were more likely to request a CBT referral. Table 8 presents the regression coefficients, Wald statistics, and odds ratios for each of the predictors and covariates.

Finally, in order to explore socioeconomic status, conceptualization of social anxiety, and initial anxiety change expectations as potential moderators, I included these variables as interaction terms in the primary ANCOVA models. The ANCOVA results are presented in Table 9. Note that sphericity could not be assumed for perceived helpfulness of CBT exposure techniques to address social anxiety, so a GreenhouseGeisser correction was used. None of the three variables significantly moderated the rationale condition's effect on the primary dependent variables.

\section{$\underline{\text { Ancillary Analyses }}$}

In order to further replicate the work of Ahmed and Westra (2009), I conducted three hierarchical regression analyses to examine whether adaptive changes (from pre- to post-rationale) in the primary dependent variables were associated with conducting specific therapeutic actions at 2-week follow-up (time 3). The hierarchical regression analyses are shown in Table 10. Specific therapeutic action at follow-up was the dependent variable for all three models, while anxiety change expectations, perceived confidence in conducting CBT exposure techniques to address social anxiety, and perceived helpfulness of exposure techniques were the independent variables. In each model, baseline scores of the independent variable of interest and action toward change 
(i.e., whether the participant was taking action toward fixing his/her problem) were controlled for. In these analyses, it was important to control for baseline action toward change while examining increases in therapeutic actions at follow-up. Although the hierarchical regression models were statistically significant, no model showed that the independent variables of interest contributed significantly to the variance explained; that is, adaptive changes in anxiety change expectations, perceived confidence in conducting CBT exposure techniques, and perceived helpfulness of exposure techniques did not significantly predict specific therapeutic actions at 2-week follow-up.

Replicating Ahmed and Westra (2009), I also conducted one linear regression analysis to see if baseline anxiety change expectations predicted specific therapeutic actions at follow-up. The result was not significant, $t(176)=1.11, p=.27$. 


\section{CHAPTER 4}

\section{DISCUSSION}

The purpose of this study was to replicate and extend the work of Ahmed and Westra (2009) by examining how expectancy persuasion techniques, delivered in the context of a treatment rationale presentation, influence analogue patients' post-rationale treatment beliefs, treatment motivation, social anxiety symptoms, and therapeutic actions. Consistent with my prediction, there were significant increases from pre- to post-rationale presentation (time 1 to time 2 ) in anxiety change expectations, perceived confidence in conducting CBT exposure techniques to address social anxiety, and perceived helpfulness of exposure techniques, across both groups. Further, across the three time points there was a significant main effect of time on those same variables. Counter to my predictions, no other effects of time, group, or their interaction emerged for the various dependent variables. Additionally, an exploration of socioeconomic status, conceptualization of social anxiety, and initial anxiety change expectations as potential moderators revealed no significant findings. Finally, ancillary analyses showed that the primary variables of interest did not significantly predict specific therapeutic actions at 2-week follow-up.

The findings that the presentation of a treatment rationale significantly increased the primary outcomes replicate those of Ahmed and Westra (2009), and point to the seeming clinical value of providing patients with a clear and compelling formulation of an anticipated treatment approach. Irrespective of treatment type, a clear treatment rationale lends valuable contextual meaning, and it provides patients with an opportunity to assess treatment fit and to engage their hope for change (e.g., Anderson, Lunnen, \& Ogles, 2010; Frank, 1961). In many ways, the provision of a treatment rationale may be a quintessential transdiagnostic factor early in psychotherapy that forms the conceptual 
backdrop of the subsequent treatment process (Constantino, Boswell, Bernecker, \& Castonguay, 2013). These results suggest that for highly socially anxious participants, laying this groundwork for treatment through the provision of a rationale may promote increased self-efficacy for managing symptoms, perceived confidence in conducting the necessary tasks of treatment (i.e., exposure techniques), and perceived helpfulness of those exposure techniques to address symptoms. The specific finding that confidence in treatment techniques increases following the presentation of a treatment rationale is also consistent with more recent work in psychodynamic therapy (Goldman, Hilsenroth, Owen, \& Gold, 2013).

It is important to note that treatment rationale provision did not have a uniformly significant effect on all dependent variables. Specifically, the slopes of the secondary variables of general psychotherapy outcome expectations, attitudes toward seeking psychological help, motivation for future engagement in psychotherapy, and social anxiety did not change across the three time points. Although these non-significant findings are somewhat surprising, it is possible that there was something qualitatively different about these variables in comparison to the primary outcomes. Perhaps the most persuasive element of this particular rationale was the discussion of the effectiveness (at least conceptually and logically) of exposing oneself to anxiety-provoking stimuli in the service of habituation and anxiety reduction. It is plausible that while one could be influenced to believe more firmly in a conceptually presented treatment technique for social anxiety, more global beliefs like general treatment outcome expectations, attitudes toward seeking any psychological help, and future engagement in any therapy would be less impacted. Further, the provision of a treatment rationale is only a starting point in 
therapy, and changing one's anxiety symptoms to a significant degree may require actual active engagement in treatment. It will be important for future research to continue to examine the differential influences of a treatment rationale, and its persuasive components, on various types of treatment beliefs and elements of psychological functioning.

Contrary to my hypothesis, no statistically significant differences were found between the expectancy persuasion group and comparison group on the primary or secondary dependent variables. These results do not replicate the experimental work of Constantino, Klein, Smith-Hansen, and Greenberg (2009) and Kazdin and Krouse (1983), which suggested that certain expectancy persuasion methods (similar to those in the current study) could influence positive changes in patients' treatment beliefs and psychological functioning. The lack of between-group findings regarding the primary variables may be partially related to a compromised salience of the expectancy persuasion techniques embedded within the rationale video. It is possible that seeing a credible therapist present a CBT for social anxiety rationale, which included a discussion about its empirical support, concealed the efficacy of the expectancy persuasion techniques making them less prominent for participants. Put another way, the expectancy persuasion techniques may not have been potent enough over and above the basic rationale delivery to allow experimental group participants to benefit from their influence. From a research design standpoint, this concern might be remedied in future research by reducing the amount of discussion on the nature of CBT in the control group, and including the persuasion techniques (i.e., hope-inspiring statements, highlighting empirical support for CBT for social anxiety, socializing the patient to the treatment 
process, using technical jargon, and discussing the broad effects of the treatment) more frequently throughout the rationale in the experimental group. Alternatively, it could simply be that the persuasiveness of a therapy or therapist lies largely in the unenhanced delivery of a logical treatment rationale.

Another possible explanation of no significant between-group findings is that there is something qualitatively different about socially anxious students that made the expectancy persuasion methods less effective. Constantino et al. (2009) studied CBT in a clinically depressed sample, while Kazdin and Krause (1983) examined an unselected undergraduate sample in their study. Whereas Kazdin and Krause found that a therapist's broad focus on affect, cognition, and behavior was an important component of their treatment rationale, it is plausible that socially anxious individuals are not looking for a treatment that will have a broad impact on their functioning, but rather one that will help them reduce their anxiety in the short term when they speak in front of the class, socialize at a party, etc. On the other hand, individuals with more diffuse or complicated distress might be influenced by the idea that the treatment has a broad effect on functioning. Thus, it will be important for future research to parse out the differential influences of a treatment rationale on individuals with a broad range of diagnoses (thereby helping to further contribute to the long-standing question in psychotherapy research of what works for whom under what conditions?).

Regarding the non-significant effect of rationale condition on the secondary outcome variables of therapeutic actions, it is possible that the 2-week period between times 2 and 3 was not sufficient to allow participants to take action toward seeking therapy and/or exposing themselves to anxiety provoking stimuli in the service of 
reducing anxiety. In this study, a longer follow-up period was precluded because of feasibility concerns. However, future studies should consider including an extended follow-up period as was done in Ahmed and Westra (2009).

Another possible explanation for the non-significant between-condition effects on the outcomes is that there are moderating conditions under which persuasion tactics would be more or less beneficial. However, my exploratory moderator analyses revealed that our theoretically pre-determined moderators of socioeconomic status, conceptualization of social anxiety, and initial anxiety change expectations did not interact with rationale condition to influence the three primary dependent variables, suggesting that they may not be relevant when it comes to the differential effects of a rationale on treatment beliefs. First, it is possible that socioeconomic status is not a determinant of exposure to psychotherapy, as I theoretically posited, which would undermine the notion that lower SES individuals might derive greater benefit from expectancy persuasion methods because they have less familiarity with psychotherapy and thus have more to gain from the persuasion techniques. Second, conceptualization of social anxiety is likely a complex variable. Individuals may conceptualize their social anxiety as caused by a combination of psychological and biological factors. Thus, the video's focus on a psychosocial approach to treating social anxiety may have an impact on all participants, not just those who have a primarily psychological conceptualization. Finally, I hypothesized that participants with an initially low level of anxiety change expectations might have more room to benefit from the expectancy persuasion techniques than those individuals with initially high expectations; however, this was not the case. It is possible that most individuals who struggle with social anxiety have low presenting 
levels of anxiety change expectations (a characteristic that might partially help to maintain their symptoms). This would suggest that a majority of participants had the room to benefit from the expectancy persuasion techniques because few had initially high anxiety change expectations. Thus, there was not a moderating effect of anxiety change expectations in this sample. Given these non-significant interaction effects, future work will need to explicate the precise conditions under which expectancy persuasion techniques could be most effective.

Lastly, the ancillary analyses showed that the primary variables of interest (i.e., anxiety change expectations, perceived confidence in conducting CBT exposure techniques, and perceived helpfulness of exposure techniques) did not significantly predict specific therapeutic actions at 2-week follow-up, nor were baseline anxiety change expectations associated with specific therapeutic actions at follow-up. This is consistent with Ahmed and Westra's (2009) finding that post-rationale anxiety change expectations did not significantly predict interpersonal exposure frequency at 1-month follow-up, but contrary to their finding that baseline anxiety change expectations did predict these follow-up actions. Additionally, the results are inconsistent with their findings that improvements in perceived confidence in conducting exposure techniques and perceived helpfulness of exposure techniques significantly predicted interpersonal exposure frequency at 1-month follow-up. As discussed earlier, the 2-week period between times 2 and 3 in the current study may not have been sufficient to allow participants to expose themselves to anxiety-provoking stimuli in the service of reducing anxiety. Thus, it remains possible that a positive response to a treatment rationale would have been associated with conducting therapeutic actions had the follow-up period been 
extended. As it stands, though, my findings render the literature on this question currently mixed (thereby calling for clarifying research, perhaps with different follow-up time periods to compare and contrast).

This study is characterized by several limitations. First, although the addition of a comparison group was an improvement over previous studies, lack of a true no rationale control group is still a limitation. Thus, the possibility remains that experimental demand or social desirability influenced the findings, as opposed to an actual rationale effect. Future research can reduce the chances of these potential confounds by including a control group that does not receive a treatment rationale.

Second, the sample was comprised of socially anxious college undergraduate students, which limits generalizability of the findings. Further, although baseline FNEB and ACES scores were close to those seen in clinical samples, conducting this research in clinical settings will be an important next step. In addition, studying non-CBT treatment rationales, and disorders beyond social anxiety, will uncover whether the findings are equivalent across treatment modalities and diagnoses.

Finally, based on the lack of between-group findings, it is possible that the expectancy video was not as different from the comparison video as suspected. If this were the case, then it would be important for future work to identify how to create therapy rationales in which the expectancy persuasion methods are more salient for participants.

Despite these limitations, this study underscores the power of the treatment rationale by replicating most aspects of Ahmed and Westra's (2009) work. Further, it improves upon past research by having used a selected sample, employing a video-based 
rationale, and including a comparison group. The lack of between-group findings does not negate the potential value of expectancy persuasion methods for impacting treatment beliefs and actions. Although the techniques used in this study did not have an impact over and above the positive influence of a treatment rationale, there is still experimental evidence that these methods can be effective (e.g., Constantino et al., 2009; Kazdin and Krouse, 1983). Thus, it will be important for future research to continue to examine psychotherapy-related expectations, and potential persuasion methods, in order to help clinicians directly influence patients' beliefs about treatment. 
Table 1: Descriptive Statistics for Participants' Sociodemographic Variables by Condition 


\begin{tabular}{|c|c|c|c|c|c|c|}
\hline Continuous Variable & $M$ & $S D$ & Range & $M$ & $S D$ & Range \\
\hline Age & 19.73 & 1.93 & $18-32$ & 19.77 & 1.39 & $18-24$ \\
\hline Categorical Variables & $n$ & & $\%$ & & $n$ & $\%$ \\
\hline \multicolumn{7}{|l|}{ Ethnicity } \\
\hline Black/Afro- & 4 & & 2.3 & & 5 & 2.8 \\
\hline Caribbean/African & 10 & & 5.7 & & 9 & 5.1 \\
\hline Asian & 70 & & 39.8 & & 66 & 37.5 \\
\hline White/European & 4 & & 2.3 & & 2 & 1.1 \\
\hline Hispanic/Latin & 4 & & 2.3 & & 1 & 0.6 \\
\hline American & 0 & & 0.0 & & 1 & 0.6 \\
\hline \multicolumn{7}{|l|}{ Biracial/Multiracial } \\
\hline Other & 27 & & 15.2 & & 23 & 12.9 \\
\hline Year in College & 32 & & 18.0 & & 23 & 12.9 \\
\hline $1^{\text {st }}$ year & 22 & & 12.4 & & 23 & 12.9 \\
\hline $2^{\text {nd }}$ year & 7 & & 3.9 & & 16 & 9.0 \\
\hline $3^{\text {rd }}$ year & 4 & & 2.2 & & 0 & 0.0 \\
\hline $4^{\text {th }}$ year & 1 & & 0.6 & & 0 & 0.0 \\
\hline \multicolumn{7}{|l|}{$5^{\text {th }}$ year } \\
\hline $6^{\text {th }}$ year + & 7 & & 4.0 & & 13 & 7.5 \\
\hline Household Income & 8 & & 4.6 & & 7 & 4.0 \\
\hline$<\$ 25,000$ & 15 & & 8.7 & & 15 & 8.7 \\
\hline$\$ 25,001-50,000$ & 12 & & 6.9 & & 11 & 6.4 \\
\hline$\$ 50,001-75,000$ & 22 & & 12.7 & & 14 & 8.1 \\
\hline$\$ 75,001-100,000$ & 4 & & 2.3 & & 12 & 6.9 \\
\hline$\$ 100,001-125,000$ & 7 & & 4.0 & & 2 & 1.2 \\
\hline$\$ 125,001-150,000$ & 7 & & 4.0 & & 6 & 3.5 \\
\hline$\$ 150,001-175,000$ & 8 & & 4.6 & & 3 & 1.7 \\
\hline \multicolumn{7}{|l|}{$\$ 175,001-200,000$} \\
\hline$\$ 200,001+$ & & & & & & \\
\hline
\end{tabular}




\begin{tabular}{|c|c|c|c|c|}
\hline \multicolumn{5}{|l|}{ Marital Status } \\
\hline Single & 71 & 39.9 & 71 & 39.9 \\
\hline Married & 14 & 7.9 & 7 & 3.9 \\
\hline Divorced & 7 & 3.9 & 7 & 3.9 \\
\hline Widowed & 1 & 0.6 & 0 & 0.0 \\
\hline \multicolumn{5}{|l|}{ Mother's Highest Level of Ed } \\
\hline$<$ high school & 2 & 1.1 & 2 & 1.1 \\
\hline High school/GED & 14 & 7.9 & 11 & 6.2 \\
\hline Some college & 12 & 6.7 & 9 & 5.1 \\
\hline 2-year college & 11 & 6.2 & 9 & 5.1 \\
\hline 4-year college & 30 & 16.9 & 29 & 16.3 \\
\hline Master's degree & 18 & 10.1 & 21 & 11.8 \\
\hline Doctoral degree & 2 & 1.1 & 3 & 1.7 \\
\hline Professional degree & 4 & 2.2 & 1 & 0.6 \\
\hline Don't know/Not applicable & 0 & 0.0 & 0 & 0.0 \\
\hline \multicolumn{5}{|l|}{ Father's Highest Level of Ed } \\
\hline$<$ high school & 1 & 0.6 & 4 & 2.3 \\
\hline High school/GED & 19 & 10.8 & 20 & 11.4 \\
\hline Some college & 9 & 5.1 & 9 & 5.1 \\
\hline 2-year college & 9 & 5.1 & 7 & 4.0 \\
\hline 4-year college & 21 & 11.9 & 19 & 10.8 \\
\hline Master's degree & 13 & 7.4 & 11 & 6.3 \\
\hline Doctoral degree & 8 & 4.5 & 6 & 3.4 \\
\hline Professional degree & 7 & 4.0 & 2 & 1.1 \\
\hline Don’t know/Not applicable & 5 & 2.8 & 6 & 3.4 \\
\hline \multicolumn{5}{|l|}{ Employment Status } \\
\hline Full-time student, & 37 & 20.8 & 34 & 19.1 \\
\hline unemployed & 51 & 28.7 & 47 & 26.4 \\
\hline $\begin{array}{l}\text { Full-time student, employed } \\
\text { part-time }\end{array}$ & 3 & 1.7 & 4 & 2.2 \\
\hline $\begin{array}{l}\text { Full-time student, employed } \\
\text { full-time }\end{array}$ & 0 & 0.0 & 0 & 00 \\
\hline $\begin{array}{l}\text { Part-time student, } \\
\text { unemploved }\end{array}$ & 1 & 0.6 & 0 & 0.0 \\
\hline $\begin{array}{l}\text { Part-time student, employed } \\
\text { part-time }\end{array}$ & 1 & 0.6 & 0 & 0.0 \\
\hline $\begin{array}{l}\text { Part-time student, employed } \\
\text { full-time }\end{array}$ & & & & \\
\hline
\end{tabular}

Note. There were no significant between condition differences on the sociodemographic variables presented. 
Table 2: Descriptive Statistics for Participants' Past Treatment History by Condition

$$
\text { Comparison }(n=93) \quad \text { Experimental }(n=85)
$$

Continuous Variables $\quad M \quad S D \quad$ Range $\quad M \quad S D$ Range

Times previously in

psychotherapy for any

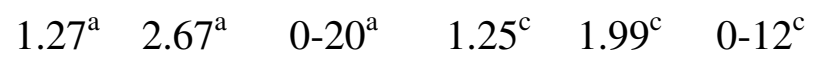

psychological difficulties

(separate courses of treatment)

$\begin{array}{lllll}.60^{\mathrm{b}} & 1.74^{\mathrm{b}} & 0-12^{\mathrm{b}} \quad .76 & 2.57 & 0-20\end{array}$

Times previously in

psychotherapy for social

anxiety concerns (separate

courses of treatment)

$\begin{array}{lllll}\text { Categorical Variables } & n & \% & n & \%\end{array}$

Participants currently in

psychotherapy for any

$\begin{array}{llll}14 & 7.8 & 15 & 8.4\end{array}$

psychological difficulties

Participants currently in

psychotherapy for social

9

5.0

8

4.5

anxiety concerns

Participants ever in

40

22.4

44

24.7

psychotherapy for any

psychological difficulties

25

14.0

25

14.0

Participants ever in

psychotherapy for social

anxiety concerns

There were no significant between condition differences on the psychotherapy history variables presented.

${ }^{a}$ Results after removal of the participant who reported going to therapy for any psychological difficulties 100 times.

${ }^{b}$ Results after removal of the participant who reported going to therapy for any social anxiety concerns 100 times.

${ }^{\mathrm{c}}$ Results after removal of the participant who reported going to therapy for any psychological difficulties 50 times. 
Table 3: Descriptive Statistics for Dependent Variables by Condition

\begin{tabular}{|c|c|c|c|c|c|c|c|c|c|c|c|c|}
\hline & \multicolumn{6}{|c|}{$\underline{\text { Comparison Group }(n=93)}$} & \multicolumn{6}{|c|}{$\underline{\text { Experimental Group }(n=85)}$} \\
\hline & \multicolumn{2}{|c|}{$\underline{\text { Time } 1}$} & \multicolumn{2}{|c|}{$\underline{\text { Time } 2}$} & \multicolumn{2}{|c|}{$\underline{\text { Time } 3}$} & \multicolumn{2}{|c|}{$\underline{\text { Time } 1}$} & \multicolumn{2}{|c|}{$\underline{\text { Time } 2}$} & \multicolumn{2}{|c|}{$\underline{\text { Time } 3}$} \\
\hline & $M$ & $S D$ & $M$ & $S D$ & $M$ & $S D$ & $M$ & $S D$ & $M$ & $S D$ & $M$ & $S D$ \\
\hline ACES & 73.99 & 12.55 & 75.29 & 11.89 & 76.55 & 11.96 & 73.16 & 14.82 & 74.79 & 14.62 & 75.71 & 11.91 \\
\hline PECHS (Conf) & 44.69 & 20.05 & 53.31 & 29.73 & 58.56 & 21.47 & 41.02 & 20.27 & 52.51 & 20.27 & 56.44 & 22.13 \\
\hline PECHS (Help) & 58.34 & 24.42 & 67.15 & 22.49 & 65.09 & 22.85 & 56.84 & 24.31 & 67.17 & 23.14 & 64.80 & 23.17 \\
\hline CEQ (Expectancy) & 58.60 & 21.39 & 63.01 & 19.66 & 63.48 & 21.51 & 58.45 & 22.68 & 65.18 & 22.07 & 63.65 & 20.17 \\
\hline BAPS & 79.59 & 12.33 & 82.12 & 11.27 & 82.52 & 12.36 & 80.94 & 14.89 & 83.18 & 13.69 & 84.28 & 13.92 \\
\hline CMOTS & 17.78 & 5.48 & 18.28 & 5.45 & 18.84 & 5.43 & 17.33 & 6.81 & 18.75 & 6.15 & 18.74 & 6.15 \\
\hline FNEB & 48.92 & 7.05 & 48.35 & 8.22 & 47.97 & 8.45 & 50.89 & 7.41 & 49.64 & 7.74 & 49.11 & 8.41 \\
\hline Specific Actions & -- & -- & -- & -- & 10.09 & 5.60 & -- & -- & -- & -- & 9.46 & 5.12 \\
\hline
\end{tabular}




\begin{tabular}{|c|c|c|c|c|c|c|c|c|c|c|c|c|}
\hline General Actions & -- & -- & -- & -- & 1.80 & 1.30 & -- & -- & -- & -- & 1.87 & 1.50 \\
\hline CEQ (Credibility) & -- & -- & 20.69 & 4.58 & -- & -- & -- & -- & 20.39 & 5.02 & -- & -- \\
\hline CRF-S & -- & -- & 65.39 & 10.20 & -- & -- & -- & -- & 67.66 & 11.57 & -- & -- \\
\hline
\end{tabular}

Note CEQ = Credibility and Expectancy Questionnaire (Expectancy Item); ACES = Anxiety Change Expectancy Scale; PECHS = Perceived Exposure Confidence/Helpfulness Scale (Confidence or Helpfulness subscale); BAPS = Beliefs About Psychological Services Scale; CMOTS = Client Motivation for Therapy Scale (Intrinsic Motivation subscale); FNEB = Fear of Negative Evaluation Scale (Brief Version), CEQ = Credibility and Expectancy Questionnaire (Credibility Items), CRF-S = Counselor Rating Form - Short Version. 
Table 4: Percent of Participants Missing Data by Questionnaire

\begin{tabular}{|c|c|c|c|c|c|c|}
\hline & \multicolumn{2}{|c|}{$\underline{\text { Time } 1}$} & \multicolumn{2}{|c|}{ Time 2} & \multicolumn{2}{|c|}{ Time 3} \\
\hline & $\%$ & $\begin{array}{c}\% \text { after } \\
\text { imputation }\end{array}$ & $\%$ & $\begin{array}{c}\% \text { after } \\
\text { imputation }\end{array}$ & $\%$ & $\begin{array}{c}\% \text { after } \\
\text { imputation }\end{array}$ \\
\hline ACES & 3.5 & 0 & 1.1 & 0 & 4.0 & 0 \\
\hline $\begin{array}{l}\text { PECHS } \\
\text { (Conf) }\end{array}$ & 1.1 & 1.1 & 1.1 & 1.1 & 2.3 & 1.1 \\
\hline $\begin{array}{l}\text { PECHS } \\
\text { (Help) }\end{array}$ & 1.1 & 1.1 & 1.1 & 1.1 & 1.7 & 1.1 \\
\hline BAPS & 3.5 & 0 & 2.9 & 0 & 2.9 & 0 \\
\hline CMOTS & 0.6 & 0 & 0.6 & 0 & 2.3 & 0 \\
\hline FNEB & 0.6 & 0 & 1.7 & 0 & 2.9 & 0 \\
\hline $\begin{array}{l}\text { Specific } \\
\text { Actions }\end{array}$ & -- & -- & -- & -- & 0.6 & 0.6 \\
\hline $\begin{array}{l}\text { CEQ } \\
\text { (Cred) }\end{array}$ & -- & -- & 0 & 0 & -- & -- \\
\hline CRF-S & -- & -- & 1.1 & .6 & -- & -- \\
\hline $\begin{array}{l}\text { PANAS } \\
(\mathrm{PA})\end{array}$ & 1.7 & 0 & 0 & 0 & 1.1 & 0 \\
\hline $\begin{array}{l}\text { PANAS } \\
\text { (NA) }\end{array}$ & 0.6 & 0 & 0.0 & 0 & 1.1 & 0 \\
\hline URICA & 0.6 & 0 & 1.1 & 0 & 1.7 & 0 \\
\hline
\end{tabular}

ACES = Anxiety Change Expectancy Scale; PECHS = Perceived Exposure Confidence/Helpfulness Scale (Confidence or Helpfulness subscale); BAPS = Beliefs About Psychological Services Scale; CMOTS = Client Motivation for Therapy Scale (Intrinsic Motivation subscale); FNEB = Fear of Negative Evaluation Scale (Brief Version); CEQ = Credibility and Expectancy Questionnaire (Credibility Items), CRF-S = Counselor Rating Form - Short Version, PANAS = Positive and Negative Affect Scale (Positive or Negative Affect subscale), URICA = University of Rhode Island Change Assessment. 
Table 5: Intercorrelations for Dependent Variables at Time 1

\begin{tabular}{|c|c|c|c|c|c|c|c|c|c|c|c|c|}
\hline & ACES & $\begin{array}{c}\text { PECHS } \\
\text { (Conf) }\end{array}$ & $\begin{array}{c}\text { PECHS } \\
\text { (Help) }\end{array}$ & CEQ & BAPS & CMOTS & FNEB & $\begin{array}{l}\text { Specific } \\
\text { Actions }^{\mathrm{a}}\end{array}$ & $\begin{array}{l}\text { General } \\
\text { Actions }^{\mathrm{a}}\end{array}$ & $\begin{array}{c}\text { CEQ } \\
(\text { Cred })^{b}\end{array}$ & $\mathrm{CRF}^{-\mathrm{S}^{\mathrm{b}}}$ & $\operatorname{Ref}^{b}$ \\
\hline ACES & 1.00 & $.28 * *$ & $.25^{* *}$ & $.26 * *$ & $.37 * *$ & $.26 * *$ & $-.25 * *$ & .08 & -.07 & .12 & .07 & -.08 \\
\hline $\begin{array}{l}\text { PECHS } \\
\text { (Conf) }\end{array}$ & & 1.00 & $.56^{* *}$ & $.164 *$ & .06 & .05 & $-.16^{*}$ & $.32 * *$ & $-.16^{*}$ & .11 & .09 & .00 \\
\hline $\begin{array}{l}\text { PECHS } \\
\text { (Help) }\end{array}$ & & & 1.00 & .08 & .13 & .05 & -.12 & $.26^{* *}$ & -.06 & $.21 * *$ & .11 & -.11 \\
\hline CEQ & & & & 1.00 & $.45^{* *}$ & $.38 * *$ & .00 & .09 & $.19 *$ & $.23 * *$ & $.18^{*}$ & .02 \\
\hline BAPS & & & & & 1.00 & $.44 * *$ & .05 & -.04 & $.26 * *$ & $.36 * *$ & $.19 * *$ & .12 \\
\hline CMOTS & & & & & & 1.00 & .09 & .10 & .11 & $.37 * *$ & $.17^{*}$ & $\begin{array}{c}.21^{*} \\
*\end{array}$ \\
\hline FNEB & & & & & & & 1.00 & .00 & .11 & .06 & .00 & $\begin{array}{c}.22^{*} \\
*\end{array}$ \\
\hline $\begin{array}{l}\text { Specific } \\
\text { Actions }\end{array}$ & & & & & & & & 1.00 & .09 & .04 & .03 & .04 \\
\hline $\begin{array}{l}\text { General } \\
\text { Actions }\end{array}$ & & & & & & & & & 1.00 & .04 & .01 & .08 \\
\hline
\end{tabular}


Cred)

Note. ACES = Anxiety Change Expectancy Scale; PECHS = Perceived Exposure Confidence/Helpfulness Scale $($ Confidence or Helpfulness subscale $) ;$ CEQ = Credibility and

Expectancy Questionnaire (Expectancy Item); BAPS = Beliefs About Psychological Services Scale; CMOTS = Client Motivation for Therapy Scale (Intrinsic Motivation subscale) FNEB = Fear of Negative Evaluation Scale (Brief Version); CEQ = Credibility and Expectancy Questionnaire (Credibility Items), CRF-S = Counselor Rating Form - Short Version $* * p<.01$

$* p<.05$

${ }^{a}$ This measure was given only at Time 3 .

${ }^{\mathrm{b}}$ This measure was given only at Time 2 
Table 6: Intercorrelations for Proposed Covariates and Dependent Variables

\begin{tabular}{|c|c|c|c|c|}
\hline & BSI & $\begin{array}{c}\text { PANAS } \\
(\mathrm{PA})\end{array}$ & $\begin{array}{c}\text { PANAS } \\
\text { (NA) }\end{array}$ & URICA \\
\hline ACES & $-.58 * *$ & $.28 * *$ & $-.29 * *$ & $.31 * *$ \\
\hline PECHS (Help) & $-.19 * *$ & $.31 * *$ & .01 & .14 \\
\hline PECHS (Conf) & $-.22 * *$ & $.35 * *$ & -.10 & $.17 *$ \\
\hline CEQ & -.03 & $-.19 *$ & -.09 & $.33 * *$ \\
\hline BAPS & -.10 & $.17 *$ & -.09 & $.26^{* *}$ \\
\hline CMOTS & .12 & $.35 * *$ & .08 & $.24 * *$ \\
\hline FNEB & $.39 * *$ & -.07 & $.27 * *$ & -.02 \\
\hline Specific Actions & .10 & .13 & .14 & $.21 * *$ \\
\hline General Actions & $.21 * *$ & -.02 & $.15^{*}$ & .13 \\
\hline CEQ (Cred) & .04 & $.24 * *$ & .08 & .13 \\
\hline CRF-S & -.00 & .07 & -.09 & .01 \\
\hline Referral & $.29 * *$ & .05 & $.33 * *$ & .00 \\
\hline
\end{tabular}

Note . ACES = Anxiety Change Expectancy Scale; PECHS = Perceived Exposure Confidence Helpfulness Scale (Confidence or Helpfulness subscale); CEQ = Credibility and Expectancy Questionnaire (Expectancy Item); BAPS = Beliefs About Psychological Services Scale; CMOTS = Client Motivation for Therapy Scale (Intrinsic Motivation subscale); FNEB = Fear of Negative Evaluation Scale (Brief Version); CEQ = Credibility and Expectancy Questionnaire (Credibility Items), CRF-S = Counselor Rating Form - Short Version.

$* * p<.01$

$* p<.05$ 
Table 7: ANCOVA Results for Time (Within Subjects), Condition (Between Subjects), and their Interaction

\begin{tabular}{|c|c|c|c|c|c|c|c|c|c|}
\hline & $\begin{array}{c}\text { Within Subjects } \\
F\end{array}$ & $p$ & $\begin{array}{l}\text { Partial } \\
\eta^{2}\end{array}$ & $\begin{array}{c}\text { Between } \\
\text { Subjects } \\
\quad F\end{array}$ & $p$ & $\begin{array}{l}\text { Partial } \\
\eta^{2}\end{array}$ & $\begin{array}{c}\text { Time } \mathrm{x} \text { Condition } \\
F\end{array}$ & $p$ & $\begin{array}{l}\text { Partial } \\
\eta^{2}\end{array}$ \\
\hline ACES & $(2,344)=3.39$ & .04 & .02 & $(1,172)=.19$ & .66 & .001 & $(2,344)=.10$ & .91 & .001 \\
\hline $\begin{array}{l}\text { PECHS } \\
\text { (Conf) }\end{array}$ & $(2,342)=10.55$ & $<.001$ & .06 & $(1,171)=.41$ & .52 & .002 & $(2,342)=.78$ & .46 & .01 \\
\hline $\begin{array}{l}\text { PECHS } \\
\text { (Help) }\end{array}$ & $\begin{array}{l}(1.76,302.63)= \\
5.28\end{array}$ & $<.01$ & .03 & $(1,172)=.03$ & .87 & .00 & $\begin{array}{l}(1.76,302.63)= \\
.16\end{array}$ & .85 & .001 \\
\hline $\begin{array}{l}\text { CEQ } \\
\text { (Expect) }\end{array}$ & $\begin{array}{l}(1.86,316.19)= \\
.01\end{array}$ & .98 & .00 & $(1,170)=.05$ & .82 & .00 & $\begin{array}{l}(1.86,316.19)= \\
.22\end{array}$ & .78 & .001 \\
\hline BAPS & $(2,342)=1.46$ & .23 & .01 & $(1,171)=.84$ & .36 & .01 & $(2,342)=.24$ & .79 & .001 \\
\hline CMOTS & $\begin{array}{l}(1.93,335.56)= \\
1.69\end{array}$ & .19 & .01 & $(1,174)=.00$ & .99 & .00 & $\begin{array}{l}(1.93,335.56)= \\
1.03\end{array}$ & .36 & .01 \\
\hline
\end{tabular}




\begin{tabular}{lllllllllll} 
FNEB $\quad(2,340)=1.57$ & .21 & .01 & $(1,170)=1.1$ & .29 & .01 & $(2,340)=.79$ & .45 & .01 \\
\hline
\end{tabular}

Note. CEQ = Credibility and Expectancy Questionnaire (Expectancy Item); ACES = Anxiety Change Expectancy Scale; PECHS = Perceived Exposure Confidence/Helpfulness Scale (Confidence or Helpfulness subscale); BAPS = Beliefs About Psychological Services Scale; CMOTS = Client Motivation for Therapy Scale (Intrinsic Motivation subscale); FNEB = Fear of Negative Evaluation Scale (Brief Version). Partial $\eta^{2}=$ effect size (partial eta squared). Small effect $=.01$; medium effect $=.06$; large effect $=.14$. 
Table 8: Logistic Regression Results Predicting Requests for CBT Referrals

\begin{tabular}{|c|c|c|c|c|c|}
\hline & $B$ & Wald & $p$ & $\operatorname{Exp}(B)$ & $95 \%$ CI for $\operatorname{Exp}(B)$ \\
\hline Condition & .74 & 3.25 & .07 & 2.09 & $.94-4.66$ \\
\hline BSI & .01 & 3.01 & .08 & 1.01 & $.99-1.02$ \\
\hline $\begin{array}{l}\text { PANAS } \\
\text { (NA) }\end{array}$ & .08 & 7.30 & .007 & 1.08 & $1.02-1.14$ \\
\hline
\end{tabular}

Note BSI $=$ Brief Symptom Inventory, PANAS $=$ Positive and Negative Affect Scale (Negative Affect subscale), CI $=$ confidence interval. 
Table 9: ANCOVA Results for Moderation Analyses

\begin{tabular}{|c|c|c|c|c|c|c|c|c|c|}
\hline & $\begin{array}{c}\text { Time } \mathrm{x} \\
\text { Condition } \mathrm{x} \\
\text { Income } F\end{array}$ & $p$ & $\begin{array}{c}\text { Partial } \\
\eta^{2}\end{array}$ & $\begin{array}{c}\text { Time } \mathrm{x} \\
\text { Condition } \mathrm{x} \\
\text { SAConcept } F\end{array}$ & $p$ & $\begin{array}{c}\text { Partial } \\
\eta^{2}\end{array}$ & $\begin{array}{c}\text { Time } \mathrm{x} \\
\text { Condition } \mathrm{x} \\
\text { ACES } F\end{array}$ & $p$ & $\begin{array}{l}\text { Partial } \\
\eta^{2}\end{array}$ \\
\hline $\mathrm{ACES}^{\mathrm{a}}$ & $(2,330)=.24$ & .78 & .001 & $(2,340)=1.47$ & .23 & .01 & $\begin{array}{l}(2,338)= \\
1.02\end{array}$ & .36 & .01 \\
\hline $\begin{array}{l}\text { PECHS } \\
\text { (Conf) }\end{array}$ & $(2,328)=1.39$ & .25 & .01 & $(2,338)=.89$ & .41 & .01 & $\begin{array}{l}(2,338)= \\
.98\end{array}$ & .38 & .01 \\
\hline $\begin{array}{l}\text { PECHS } \\
\text { (Help) }\end{array}$ & $\begin{array}{l}(1.74,287.45) \\
=.95\end{array}$ & .38 & .01 & $\begin{array}{l}(1.75,297.52) \\
=.30\end{array}$ & .71 & .002 & $\begin{array}{l}(1.75, \\
298.63)= \\
2.40\end{array}$ & .09 & .014 \\
\hline
\end{tabular}

Note . ACES = Anxiety Change Expectancy Scale; PECHS = Perceived Exposure Confidence/Helpfulness Scale (Confidence or Helpfulness subscale); SAConcept = conceptualization of social anxiety. Partial $\eta^{2}=$ effect size (partial eta squared). Small effect $=.01$; medium effect $=.06$; large effect $=.14$.

${ }^{a}$ The third moderation analysis for the ACES is Time $x$ Condition $x$ CEQ. 
Table 10: Hierarchical regressions predicting exposure frequency at 2-week follow-up

\begin{tabular}{|c|c|c|c|}
\hline Predictors & Beta & $t$ & $p$ \\
\hline \multicolumn{4}{|l|}{ Block 1} \\
\hline Anxiety change expectancy pre-rationale & .02 & .24 & .81 \\
\hline Baseline action & .21 & 2.66 & .01 \\
\hline \multicolumn{4}{|l|}{ Block 2} \\
\hline Anxiety change expectancy post-rationale & .10 & .83 & .41 \\
\hline Predictors & Beta & $t$ & $p$ \\
\hline \multicolumn{4}{|l|}{ Block 1} \\
\hline PECHS (Conf) pre-rationale & .29 & 4.03 & .00 \\
\hline Baseline action & .17 & 2.32 & .02 \\
\hline \multicolumn{4}{|l|}{ Block 2} \\
\hline PECHS (Conf) post-rationale & .12 & 1.27 & .21 \\
\hline Predictors & Beta & $t$ & $p$ \\
\hline \multicolumn{4}{|l|}{ Block 1} \\
\hline PECHS (Help) pre-rationale & .23 & 3.17 & .002 \\
\hline Baseline action & .18 & 2.53 & .012 \\
\hline \multicolumn{4}{|l|}{ Block 2} \\
\hline PECHS (Help) post-rationale & .15 & 1.66 & .09 \\
\hline
\end{tabular}

Note. PECHS = Perceived Exposure Confidence/Helpfulness Scale (Confidence or Helpfulness subscale). 


\section{APPENDIX A \\ EXPERIMENTAL VIDEO SCRIPT}

Note that bolded text reflects expectancy strategies not included in the comparison video script.

\section{[Introduction]}

Hello - my name is Dr. William Matthews and I am a licensed clinical psychologist.

Today, I'd like to talk to you about social anxiety disorder, also known as social phobia, and its treatment. Specifically, I will discuss cognitive-behavioral therapy, or CBT, which research has shown to be effective for social anxiety problems. We call CBT an "empirically-supported treatment." Having been in clinical practice for over 30 years, I have treated many individuals who struggle with this type of anxiety and I can appreciate how challenging it can be to live with. That being said, the message that I want to get across today is that anxiety is very treatable with psychotherapy, including short-term CBT. A large percentage of socially anxious people respond well to CBT, and the overall prognosis for change is very good. If you are struggling with symptoms of social anxiety, you could definitely benefit from psychotherapy.

\section{[What is Social Anxiety?]}

So, let's first talk about the nature of social anxiety. Generally speaking, it is a fear of saying or doing something embarrassing in front of other people. People with social anxiety worry a lot that others will evaluate them negatively in some way. For example, some people might worry that there's something wrong with their speech, or that others will make fun of how they look. Also common in socially anxious people is a fear that they're not smart enough and that they will say something stupid. Many people with social anxiety complain that they're very self-conscious and that this really interferes with their daily functioning. They also often find that they're very sensitive to cues that other people might be giving off, such as when others might be disapproving, confused, or even laughing at them. However, there is also a good chance that they may be misinterpreting these cues, or at least exaggerating them.

A common trigger for socially anxious individuals is, as one might expect, being in social situations where they might be exposed to evaluation or judgment, such as public speaking. People with social anxiety will often try to avoid anxiety-provoking situations, such as parties or social gatherings. As you can see, avoidance is a central consequence of social anxiety. Although it may help reduce anxiety in the short term, it also strengthens it in the long term. Furthermore, avoidance can be significantly disruptive to a person's life. For example, it could limit career advancement, academic performance, or even relationship quality.

So, what it is the prognosis for social anxiety? The good news is that we have developed really effective treatments for people who struggle with it. Personally, I enjoy working with individuals who struggle with anxiety because they often respond to treatment and, as noted, their prognosis is very good. For example, I have treated people who have been virtually unable to leave their houses and yet 
they have recovered successfully after a course of CBT. [SHOW QUOTE \#1 ON SCREEN NOW] Thus, any struggles that you may be having with social anxiety are exactly the type for which this therapy can be effective, and I am confident that if you were to work with a CBT therapist you would be able to deal effectively with your anxiousness. But before saying more about the specifics of the treatment, let me discuss the cognitive-behavioral model (or theory) of anxiety on which it is based.

\section{[Cognitive-Behavioral Model of Social Anxiety]}

You can think of this model as a cycle. First, there's a triggering event, such as a feeling that you said the wrong thing. Second, such triggers typically give rise to a flood of negative thoughts and worry. These thoughts often contain a lot of "what ifs," such as What if I embarrass myself? Socially anxious people might also berate themselves by saying things to themselves like, "I am going to mess up," or "I'm such a failure." We call these maladaptive or dysfunctional thoughts. Third, such dysfunctional thought processes give rise to various emotions (such as shame or sadness) and physical responses (such as a racing heart, sweaty palms, or even a full-fledged panic attack). Fourth, given that these negative thoughts and physical reactions are unpleasant, you want to get rid of them, which is a natural human response. The easiest way to do so is to avoid the situation that brought them on.

Avoidance can take two forms. First, a person can stay out of the situation all together. For example, if you are afraid of interacting with people you don't know, you avoid social gatherings. This is an example of over-avoidance. The second kind of avoidance is what we call subtle-avoidance. When people subtly-avoid, they still engage in the activity. However, they try to manage their anxiety by changing things or doing things differently. For example, even though you're still sitting in a classroom full of students, you might avoid eye contact with the professor or refrain from talking to classmates. So, even though you're not avoiding the situation altogether, your anxiety is still very much "pushing you around." Unfortunately, avoidance behavior is not a long-term solution. In fact, it actually reinforces in your mind that you should be afraid of these social scenarios, which only serves to maintain, or perhaps even increase, your anxiety - thus completing the vicious cycle!

Let's quickly review the cycle. First, there is a triggering event in which you might feel like you said or did the wrong thing. Second, the trigger gives rise to worry and negative thoughts about yourself. Third, these negative thought processes lead to various emotions (such as shame or sadness) and physical responses (such as a racing heart or sweaty palms). Fourth, you react by wanting to get rid of these emotions and the easiest way to do so is to avoid the situation, or trigger, that brought them on. Avoidance can either be subtle, which is when you engage in the situation, but try to change things about it to make yourself less anxious, or it can take the form of over-avoidance, which is when you stop engaging in the activities that bring on anxiety. In the end, both types of avoidance reinforce in your mind that you should be afraid of social situations.

\section{[Spotlight on Avoidance]}


Within the cycle that I have just explained, avoidance is probably the most important part. You can talk to yourself until you're blue in the face about how you know the probability of embarrassing yourself is not that high. However, unless you start a conversation with a stranger, or walk into that crowd, you will never experience that your greatest fears are inaccurate. Therefore, avoidance is critical because it is the number one factor that maintains your anxiety.

Sometimes I will say to people, I know how you can create an anxiety problem. All you have to do is simply decide what you are afraid of and keep avoiding it. This avoidance creates a short-term relief - ahhh, I don't have to go to that party - but, one pays a price in the long run and it actually increases anxiety in the end.

Avoidance can be a problem for many other reasons. For example, people don't get to do the kinds of things that they'd really like to do, such as dating, going to a party, conversing with people, or getting on a bus and going from point $\mathrm{A}$ to point $\mathrm{B}$ conveniently. Often these things are really important to peoples' lives and avoiding them can have negative consequences. Thus, a key take home message is that avoidance is not the solution to anxiety. So, if avoidance is the central factor in terms of maintaining anxiety, how can we treat it?

\section{[CBT \& Social Exposure]}

Well, one way to treat it is with psychotherapy, or talk therapy. As I mentioned before, one type of psychotherapy, based on the model I just described, is known as cognitivebehavioral therapy, or CBT. Many research trials suggest that CBT is one of the most effective methods for treating social anxiety. With its research-informed and novel techniques, socially anxious people who participate in CBT tend to get significantly better than people who simply try to deal with their symptoms on their own. What is even more exciting about CBT for social anxiety is that this positive effect is durable; that is, people tend to maintain their gains even after completing treatment (and they do so more than people who have been treated with anxiety medications only). Thus, I can say confidently that almost all people experience at least some benefit after going through outpatient CBT, and a good portion experience almost complete removal of their symptoms.

CBT is a treatment that will help teach you skills that you can use on your own both between sessions and after treatment ends. We know that most people can learn these skills in a fairly timely manner with regular attendance and effort in treatment. CBT has a broad focus on cognitions, emotions, and behaviors. When used to address social anxiety, one key element of this approach is called exposure. Let's take an example. Suppose a friend came to you with a phobia of dogs and said, "You know, I can barely leave my apartment because I'm afraid I'll run into a dog." Now, if that same friend came to you and said, "I'm sick of living my life this way, this dog phobia has to go," what would tell your friend to do? I might find a small, friendly dog for the two of us to work with. We could begin exposing this person to the dog on the other side of the room. Then, we would gradually approach the dog. Once this interaction 
was successful, we might move on to petting the dog and ultimately interacting with larger, more intimidating dogs.

This is a great example of the exposure portion of CBT treatment. Of course, in social anxiety, it would take a different form because we would be using social settings instead of dogs! For example, we might be making eye contact with a stranger and working our way up to beginning a conversation with a stranger. A central point is that you actually have to experience your anxiety to get over it - there is no short cut around it. It's kind of the opposite of what you might think you need to reduce your anxiety. Doing the opposite is very hard, and I understand that from watching the people with whom I work initially struggle through these exposure exercises. I also know that the more people engage in these exposure activities, the more they learn that their greatest fears will not come true, or that things are not nearly as bad as they thought. With such learning experiences, their anxiety will begin to decrease. We call this a "corrective experience." Be aware, there is no substitute for being in the situation and feeling the anxiety. When you are first going through exposure exercises, you might feel like you are not making progress or that it is counterproductive to induce anxiety in yourself, but stick with it. I have taken hundreds of people through these exposurebased treatments and they really do work for many people. The more you expose yourself to anxiety-provoking situations, and the less you avoid them, the more effective the treatment will be! In this sense, I believe that you have a say over changing your life and any anxiety problems that you currently experience. Throughout the course of therapy, if indeed you were to engage in CBT, you would start to see that you could respond to different situations more effectively. You would also notice that just because you have done things a certain way in the past does not lock you into that pattern now or in the future.

There are a few principles of exposure that I want to share with you. First, to be effective, exposure needs to be done repeatedly; it's not enough to ride the bus once. Second, it is important to identify subtle avoidance strategies and to do exposure without those "safety signals." Third, it is important to note that physiological symptoms, such as sweaty palms, are not dangerous. In fact, they can be useful when we are facing a true threat. With many types of anxiety, though, the threat is exaggerated in our head or not real at all. Finally, exposure in CBT is often done gradually, like in the dog-phobia example, so that the anxiety is not full-force right from the start. Put differently, my goal as a CBT therapist is not to flood you with anxiety, but rather to help guide you through graded, or gradual, exposures. Again, I am sensitive to the challenge of putting yourself in these anxiety-provoking situations, but getting through them is exactly what helps reduce your symptoms.

Let's review the principles of exposure that I just discussed. First, exposure must be done repeatedly to be effective. Second, it should be done without "crutches" or "safety signals" because these are subtle-avoidance strategies. Third, physiological symptoms that you might experience during exposure are not dangerous. Finally, exposure can, and should, be done gradually so that your anxiety is not full-blown right at the start. 
Let me share one exposure tool that we use in CBT, which is called a fear hierarchy. A fear hierarchy can take the form of a list of situations that make you anxious. As someone who is socially anxious and fears negative evaluation, you might include things like sitting close to the front of class or making a speech in public. Once you create your list, you rate your anxiety in each situation on a scale from $0-100$, where 0 is feeling completely relaxed and 100 is feeling extreme anxiety. We call these ratings subjective units of distress, or SUDS, and we use them frequently in CBT. After you rate each situation, you expose yourself to the lower-rated ones and work your way up in order to build your confidence. The idea is to expose yourself eventually to the higher-rated items and to sit with the anxiety until you feel it start to decrease. From experience, I know that it will take more than one exposure session to reduce your anxiety to the level you would like. Although CBT is a relatively short-term treatment, change is not always immediate and that is okay and to be expected. A vital principle is that you need to stay with the exposure until you actually experience decreased anxiety (we call this habituation). Quitting the exposure before then is another form of avoidance, which would just engage the cycle all over again!

You now know what some CBT tools are, such as exposure exercises and fear hierarchies. But what is the exact nature of the treatment? Well, CBT for social anxiety generally lasts somewhere around 20 sessions, but it can also be shorter or longer depending on your presenting concerns. During the first few sessions, the therapist will simply learn about your symptoms and your anxiety triggers. Then, your therapist will generally teach you how to identify your maladaptive thoughts (those are the ones that tell you not to go to the party because you will embarrass yourself) and work with you to alter some of those thoughts to be more accurate and logical. You will also create your fear hierarchy and try to gradually engage in as many exposure exercises as possible using your hierarchy as a guide. Your therapist will likely ask you to complete "homework" assignments, which help you to practice the skills you learn during sessions and are important to your progress. Relaxation strategies can also be helpful to practice during this process. Engaging in therapy for social anxiety, or any other difficulty, is certainly challenging. Sometimes it might feel like you are not making progress or that you are even having more symptoms than before. Rest assured that this is normal. Like I said earlier, CBT is a relatively short-term treatment, but change is not always immediate or linear (and that is okay and typical).

After going through CBT, people tend to see very broad effects. Behaviorally, they can engage in more activities than they could in the past because they are less fearful and less anxious. Overall, their mood improves and they have a higher quality of life. They also see that their thinking has fundamentally changed. They no longer worry that people at the party are negatively evaluating them; instead, they think about how fun parties have been in the past and how the anxiety will reduce eventually (we call this peaking and passing). Research also points to the effects being long lasting. Like I mentioned earlier, even after treatment ends people continue to reduce their symptoms further. We believe that this happens because you will develop more control over managing difficult problems and you will be able 
to rely on your own more adaptive coping abilities. When we start to see changes in your life, we would focus on relating these changes to your own efforts both in therapy and outside of therapy. CBT therapists can provide you with tools, but you are the one who would be using them. With this process, you can build on past successes and draw on your strengths.

I have discussed a lot with you today. As a quick review, I explained the characteristics of social anxiety and its triggers. I discussed a central element that maintains the disorder, avoidance. I also provided an overview of an empirically supported treatment for addressing social anxiety called cognitive-behavioral therapy, including its key component of exposure to anxiety provoking stimuli. Lastly, I gave you a quick overview of what a course of CBT might look like. Now, I hope you can see that your struggles with social anxiety are exactly the type for which CBT can be helpful. As I noted earlier, I am confident that if you were to work with a CBT therapist in the future, you would be able to conquer your social anxiety symptoms. But remember, you are the expert in knowing yourself, and any therapist would need to draw on that expertise as you progressed in your work together. As the expert in CBT, your therapist will be a valuable guide. However, collaboration will be essential, as only you know your innermost experiences and fears, as well as the pace at which you change most effectively. I hope that you will consider CBT if your social anxiety is interfering in any way in your life. I really do think it can help. In fact, if any of the experiences that I discussed seem relevant to you, you may be interested in taking action. If you want to look into treatment, including CBT, please indicate that, when asked, in the survey that you will now complete. We can then provide you with information. 


\section{APPENDIX B \\ COMPARISON VIDEO SCRIPT}

\section{[Introduction]}

Hello - my name is Dr. William Matthews and I am a licensed clinical psychologist. Today, I'd like to talk to you about social anxiety disorder, also known as social phobia, and its treatment. Specifically, I will discuss cognitive-behavioral therapy, or CBT, which research has shown to be effective for social anxiety problems. We call CBT an "empirically-supported treatment."

\section{[What is Social Anxiety?]}

So, let's first talk about the nature of social anxiety. Generally speaking, it is a fear of saying or doing something embarrassing in front of other people. People with social anxiety worry a lot that others will evaluate them negatively in some way. For example, some people might worry that there's something wrong with their speech, or that others will make fun of how they look. Also common in socially anxious people is a fear that they're not smart enough and that they will say something stupid. Many people with social anxiety complain that they're very self-conscious and that this really interferes with their daily functioning. They also often find that they're very sensitive to cues that other people might be giving off, such as when others might be disapproving, confused, or even laughing at them. However, there is also a good chance that they may be misinterpreting these cues, or at least exaggerating them.

A common trigger for socially anxious individuals is, as one might expect, being in social situations where they might be exposed to evaluation or judgment. Thus, for many people, triggers take the form of public speaking, reading, or writing, or just about any situation where they are the center of attention and other people are noticing them. People with social anxiety will often try to avoid anxiety-provoking situations, such as parties, social gatherings, or any places or functions with a lot of people. Some might even avoid taking classes where they know there is a graded presentation element to it! As you can see, avoidance is a central consequence of social anxiety. Although it may help reduce anxiety in the short term, it also strengthens it in the long term. Furthermore, avoidance can be significantly disruptive of a person's life. For example, it could limit career advancement, academic performance, or even relationship quality.

To review, social anxiety is a fear of saying or doing something stupid or embarrassing in front of others. Common triggers are social situations where the person might be exposed to scrutiny or judgment. A primary behavioral consequence, which is actually a maladaptive coping strategy, involves avoidance of social situations. And even when socially anxious people do not avoid, they often have to endure anxiety-provoking situations with great stress; which, like avoidance, can interfere significantly with one's functioning.

\section{[Cognitive-Behavioral Model of Social Anxiety]}

Now I am going to discuss the cognitive-behavioral model of anxiety; you can think of this model as a cycle. First, there's a triggering event, such as a feeling that you said the wrong thing or that someone is disapproving of you. Second, such triggers typically give 
rise to a flood of negative thoughts and worry. These thoughts often contain a lot of "what ifs," such as - What if I embarrass myself? What if people see me as a fool? What if someone doesn't like me? What if I make a mistake? Socially anxious people might also berate themselves by saying things to themselves like, "I am going to mess up," or "I'm such a failure." Third, such negative thought processes give rise to various emotions (such as shame or sadness) and physical responses (such as a racing heart, sweaty palms, or even a full-fledged panic attack). Fourth, given that these negative thoughts and physical reactions are unpleasant, you want to get rid of them, which is a natural human response. The easiest way to do so is to avoid the situation, or trigger, that brought them on.

Avoidance can take two forms. First, a person can stay out of the situation all together. For example, if you are afraid of interacting with people you don't know, you avoid parties or gatherings. If you are afraid of big crowds, you avoid places like the bus, the mall, concerts, or sporting events. These are examples of over-avoidance. The second kind of avoidance is what we call subtle-avoidance, which is very common in social anxiety. When people subtly-avoid, they still engage in the activity. However, they try to manage their anxiety by changing things or doing things differently. For example, even though you're still sitting in a classroom full of students, you might avoid eye contact with the professor, refrain from talking to classmates, or only raise your hand when you're certain that you know the answer (and, thus, cannot be ridiculed for getting it wrong). As another example, if you're on the bus you might be listening to your iPod to maintain a sort of distance from others. Or, you might go to great lengths to ride the bus at times when there are few people on it. You might even pretend to be texting when passing others so as to avoid having to say "hi" or having to engage in small talk. So, even though you're not avoiding social situations altogether, your anxiety is still very much "pushing you around." The anxiety is influencing you to behave in certain ways because you're predicting that bad things will happen in these settings. Unfortunately, avoidance behavior is not a long-term solution. In fact, it actually reinforces in your mind that you should be afraid of these social scenarios, which only serves to maintain, or perhaps even increase, your anxiety - thus completing the vicious cycle!

Let's quickly review the cycle. First, there is a triggering event in which you might feel like you said or did the wrong thing. Second, the trigger gives rise to worry and negative thoughts about yourself. Third, these negative thought processes lead to various emotions (such as shame or sadness) and physical responses (such as a racing heart or sweaty palms). Fourth, you react by wanting to get rid of these emotions and the easiest way to do so is to avoid the situation that brought them on. Avoidance can either be subtle, which is when you engage in the situation, but try to change things about it to make yourself less anxious, or it can take the form of over-avoidance, which is when you stop engaging in the activities that bring on anxiety. In the end, both types of avoidance reinforce in your mind that you should be afraid of social situations.

\section{[Spotlight on Avoidance]}

Within the cycle that I have just explained, avoidance is probably the most important part. You can talk to yourself until you're blue in the face about how you know the 
probability of embarrassing yourself is not that high. However, if you are not starting a conversation with a stranger, or if you are not getting on that bus or walking into that crowd, it will always be a theory and it will never be reality. That is, you will never experience that your greatest fears are inaccurate. Therefore, avoidance is critical because it is the number one factor that maintains your anxiety.

Sometimes I will say to people, I know how you can create an anxiety problem. All you have to do is simply decide what you are afraid of and keep avoiding it. People with social anxiety will often find, as they look to their history, that they've had to leave more and more things, or find more and more ways to protect themselves from the anxiety, which has prevented them from getting better. This avoidance creates a short-term relief - ahhh, I don't have to go to that party - but, one pays a price in the long run and it actually increases anxiety in the end.

Avoidance can be a problem for many other reasons. For example, people don't get to do the kinds of things that they'd really like to do, such as dating, going to a party, conversing with people, or getting on a bus and going from point $\mathrm{A}$ to point $\mathrm{B}$ conveniently. Often these things are really important to peoples' lives and avoiding them can have negative consequences. To reiterate, there might be some relief in leaving a party early when you get anxious. However, people often say in these situations that their confidence decreases or they feel guilty because they think, "Wow, I really should have stayed and it doesn't feel good to avoid things because of anxiety." Thus, a key take home message is that avoidance is not the solution to anxiety; it doesn't make it better and it can actually magnify the problem. So, if avoidance is the central factor in terms of maintaining anxiety, how can we treat it?

\section{[CBT \& Social Exposure]}

Well, one way to treat it is with psychotherapy, or talk therapy. As I mentioned before, one type of psychotherapy, based on the model I just described, is known as cognitivebehavioral therapy, or CBT. Again, CBT is an empirically supported treatment for social anxiety. One key element of this approach is called exposure. Let's take an example. Suppose a friend came to you with a phobia of dogs and said, "You know, I can barely leave my apartment because I'm afraid I'll run into a dog, and I just can't stop worrying about dogs because they are so dangerous." Now, if that same friend came to you and said, "I'm sick of living my life this way, this dog phobia has to go," what would tell your friend to do? You don't have to say it out loud, but just kind of consider that for a few seconds [pause for 5-10 seconds]. I might find a small, friendly dog for the two of us to work with. We could begin exposing this person to the dog on the other side of the room. Then, we would gradually approach the dog. Once this interaction was successful, meaning that the dog does not attack the person as he or she expected, we might move on to petting the dog and ultimately interacting with larger, more intimidating dogs.

This is a great example of the exposure portion of CBT treatment. Of course, in social anxiety it would take a different form because we would be using social settings instead of dogs! For example, we might be making eye contact with a stranger and working our way up to beginning a conversation with a stranger. Or, a socially anxious person might 
enroll in a medium sized lecture class with a goal of enrolling in larger classes, or perhaps ones that require small group discussions or even an oral presentation. A central point is that you actually have to experience your anxiety to get over it - there is no short cut around it. It's kind of a paradox, right? It's kind of the opposite of what you might think you need to reduce your anxiety. It's your anxiety that tries to sell you on staying away from dogs, or potentially embarrassing situations when it comes to social anxiety, but in fact staying away is not a solution at all and it actually makes the problem worse. In a way, the poison is the cure! You have to do the opposite of what your anxiety is trying to talk you into doing. The more people engage in these exposure activities, the more they learn that their greatest fears will not come true, or that things are not nearly as bad as they thought. With such learning experiences, their anxiety will begin to decrease. The bottom line is that there is no substitute for being in the situation and feeling the anxiety; avoidance as a coping device does not accomplish the same thing. It only makes it worse.

There are a few principles of exposure that I want to share with you. First, to be effective, exposure needs to be done repeatedly; it's not enough to ride the bus once. It's like learning a new skill. For example, if you're learning how to play tennis, you don't go hit the ball once or twice and feel confident in that skill. The same can be said for exposure exercises. Second, it is important to do exposure without "safety signals." In other words, it is important to identify those subtle avoidance strategies, or safety signals, and remove them while doing exposure exercises. If I'm trying to be comfortable talking to you, but I've turned away and I'm not looking at you, then it's not really going to benefit me. I might as well not be talking to you at all because it's not really going to do anything in terms of reducing my anxiety about talking to others. Exposure should be done without these crutches so that you can feel anxious in the situation; it's a good thing if your heart is racing, palms are sweating, and so forth because it means the exposure has the potential to work. Third, it is important to note that these physiological symptoms are not dangerous. In fact, they can be useful when we are facing a true threat. With many types of anxiety, though, the threat is exaggerated in our head or not real at all. Finally, exposure in CBT is often done gradually, like in the dog-phobia example, so that the anxiety is not full-force right from the start.

Let's review the principles of exposure that I just discussed. First, exposure must be done repeatedly to be effective. Second, it should be done without "crutches" or "safety signals" because these are subtle-avoidance strategies. Third, physiological symptoms that you might experience during exposure are not dangerous. Finally, exposure can, and should, be done gradually so that your anxiety is not full-blown right at the start.

Let me share one exposure tool that we use in CBT, which is called a fear hierarchy. A fear hierarchy can take the form of a list of situations that make you anxious. These can be situations you completely avoid or situations in which you do not feel comfortable, but endure them with discomfort. As someone who is socially anxious and fears negative evaluation, you might include things like sitting close to the front of class, making eye contact with people you don't know, sitting on a bus in rush hour, making a speech in public, etc. The situations you include should be ones for which you eventually want to 
create an exposure exercise. Once you create your list, you rate your anxiety in each situation on a scale from $0-100$, where 0 is feeling completely relaxed and 100 is feeling extreme anxiety. There are no rules about how many situations you can add to your list, they should just be situations out of which you will create exposure exercises in the future. The goal is to get in the habit of doing exposures and facing your anxiety. Therefore, after you rate each situation, you expose yourself to the lower-rated ones and work your way up in order to build your confidence. However, doing anything rated below a 50 is probably not worth doing because your anxiety isn't high enough in those situations to make a real difference in your life. The idea is to expose yourself to the higher-rated items and sit with the anxiety until you feel it start to decrease. It will likely take more than one exposure session to reduce your anxiety to a level you would like. During the exposures you can talk to yourself and do deep-breathing exercises to stay calm. Whatever it looks like, though, a vital principle is that you need to stay with the exposure until you actually experience decreased anxiety. Quitting the exposure before then is another form of avoidance, which would just engage the cycle all over again!

I have discussed a lot with you today. Now would be a good time to reflect on what I have said [pause 1-2 seconds]. As a quick review, I explained the characteristics of social anxiety and its triggers. Social anxiety is a fear of saying or doing something embarrassing in front of other people. People with social anxiety are afraid that others will find fault with them. They worry a lot that others will evaluate them negatively in some way. For example, some people might worry that there's something wrong with their speech, or that others will make fun of how they look. Also common in socially anxious people is a fear that they're not smart enough and that they will say something stupid, causing others to ridicule them or to lose respect for them. Many people with social anxiety complain that they're very self-conscious and that this really interferes with their daily functioning. Common triggers for socially anxious people are: going to parties, speaking in front of groups, and riding public transportation.

I also discussed a central element that maintains the disorder, avoidance. This avoidance sacrifices long-term well being for short-term relief (while this may seem like a good proposition in the moment, it ends up being quite an obstacle in the long run). Avoidance can either be subtle, which is when you engage in the situation but try to change things about it to make yourself less uncomfortable, or it can take the form of over-avoidance, which is when you stop engaging in the activities that bring on anxiety.

Finally, I provided an overview of an empirically supported treatment for addressing social anxiety called cognitive-behavioral therapy, or CBT, including its key component of exposure to anxiety provoking stimuli. Remember, exposure should be done repeatedly (it's not enough to ride the bus once), gradually (because we don't want all of your anxiety to flood you during your first exposure exercise), and without the use of safety signals (because using such signals means you are engaging in subtle avoidance).

One last thing - if any of the experiences that I discussed seem relevant to you, you may be interested in taking action. In fact, if you want to look into treatment, including CBT, 
please indicate that, when asked, in the survey that you will now complete. We can then provide you with information. 


\section{APPENDIX C \\ FEAR OF NEGATIVE EVALUATION SCALE - BRIEF (FNEB)}

Read each of the following statements carefully and indicate how characteristic it is of you according to the following scale:

1 - Not at all characteristic of me

2 - Slightly characteristic of me

3 - Moderately characteristic of me

4 - Very characteristic of me

5 - Extremely characteristic of me

1. I worry about what other people will think of me even when I know it doesn't make any difference.

2. I am unconcerned even if I know people are forming an unfavorable impression of me.

3. I am frequently afraid of other people noticing my shortcomings.

4. I rarely worry about what kind of impression I am making on someone.

5. I am afraid others will not approve of me.

6. I am afraid that people will find fault with me.

7. Other people's opinions of me do not bother me.

8. When I am talking to someone, I worry about what they may be thinking about me.

9. I am usually worried about what kind of impression I make.

10. If I know someone is judging me, it has little effect on me.

11. Sometimes I think I am too concerned with what other people think of me.

12. I often worry that I will say or do the wrong things. 


\section{APPENDIX D \\ ANXIETY CHANGE EXPECTANCY SCALE (ACES)}

Listed below are a number of statements concerning beliefs about change. Please read each item carefully and circle one of the five options that best reflect how you feel about the statement right now.

1 - Strongly disagree

2 - Disagree

3 - Undecided

4 - Agree

5 - Strongly Agree

1. I feel pessimistic that my anxiety problems could ever change for the better.

$\begin{array}{lllll}1 & 2 & 3 & 4 & 5\end{array}$

2. Even though I try, nothing seems to help with my anxiety.

$\begin{array}{lllll}1 & 2 & 3 & 4 & 5\end{array}$

3. It would be extremely difficult or impossible to solve my problems with anxiety.

$\begin{array}{lllll}1 & 2 & 3 & 4 & 5\end{array}$

4. I have had some positive experiences with being able to control my anxiety through talking positively to myself.

$\begin{array}{lllll}1 & 2 & 3 & 4 & 5\end{array}$

5. My problems with anxiety are too severe to benefit from treatment.

$\begin{array}{lllll}1 & 2 & 3 & 4 & 5\end{array}$

6. Self-help methods may help others control their anxiety but they won't work for me.

$\begin{array}{lllll}1 & 2 & 3 & 4 & 5\end{array}$

7. I don't believe I will ever feel truly relaxed and not worried.

$\begin{array}{lllll}1 & 2 & 3 & 4 & 5\end{array}$


8. Facing my fears has never helped me to reduce my anxiety.

$\begin{array}{lllll}1 & 2 & 3 & 4 & 5\end{array}$

9. When I force myself to do something that scares me, often it's not as bad as I thought.

$\begin{array}{lllll}1 & 2 & 3 & 4 & 5\end{array}$

10. I have had some success in reducing my anxiety.

$\begin{array}{lllll}1 & 2 & 3 & 4 & 5\end{array}$

11. There is very little anyone could do to help me solve my anxiety problems.

$\begin{array}{lllll}1 & 2 & 3 & 4 & 5\end{array}$

12. Even when I try to talk positively to myself, it doesn't help my anxiety.

$\begin{array}{lllll}1 & 2 & 3 & 4 & 5\end{array}$

13. Positive thinking is helpful to me in managing my anxiety.

$\begin{array}{lllll}1 & 2 & 3 & 4 & 5\end{array}$

14. There is no solution to my anxiety problems.

$\begin{array}{lllll}1 & 2 & 3 & 4 & 5\end{array}$

15. I am optimistic that my anxiety can change for the better.

$\begin{array}{lllll}1 & 2 & 3 & 4 & 5\end{array}$

16. I have found that I can reduce my anxiety by telling myself to relax or by using relaxation exercises.

$\begin{array}{lllll}1 & 2 & 3 & 4 & 5\end{array}$

17. I'll never be able to control my anxiety and worry.

$\begin{array}{lllll}1 & 2 & 3 & 4 & 5\end{array}$

18. I believe it's quite possible for me to feel less worried and more relaxed. 


$\begin{array}{lllll}1 & 2 & 3 & 4 & 5\end{array}$

19. If I work hard, I can have a positive impact on my problems with anxiety.

$\begin{array}{lllll}1 & 2 & 3 & 4 & 5\end{array}$

20. There are factors contributing to my anxiety that I can learn to control.

$\begin{array}{lllll}1 & 2 & 3 & 4 & 5\end{array}$




\section{APPENDIX E \\ PERCEIVED EXPOSURE CONFIDENCE/HELPFULNESS SCALE (PECHS) \\ PECHS-Pre}

In the space below list three situations involving people that you either avoid altogether or endure with great anxiety. Make sure to list only those situations that provoke much anxiety (at least 80 out of 100, with 100 being extreme anxiety). Common examples include giving a presentation to a group, making conversation with a stranger, making eye contact when you are nervous, avoiding parties, getting on a crowded bus, stating an opinion, returning something at a store, etc.).

List three such situations in which you feel extremely afraid of being evaluated negatively. For each situation, rate (1) how much you think putting yourself into each particular situation (i.e., facing fear of that situation) would be helpful and (2) rate how confident you personally would be that you could deliberately put yourself in that situation

\section{List Anxiety Provoking Situation:}

1)

a) Anxiety rating (make sure it is at least 80 out of 100 , with $100=$ extreme anxiety):

b) Rate how much you think deliberately putting yourself in this situation would be helpful in addressing your anxiety about people:

100
Not at all helpful
Extremely Helpful

c) If you were asked to go out right now and put yourself in that situation, rate how confident you are in this moment about your ability to put yourself in that situation,

1

Not at all confident
100

Totally confident

\section{List Anxiety Provoking Situation}

2) 
a) Anxiety rating (make sure it is at least 80 out of 100 , with $100=$ extreme anxiety):

b) Rate how much you think deliberately putting yourself in this situation would be helpful in addressing your anxiety about people:

1

Not at all helpful
100

Extremely Helpful

c) If you were asked to go out right now and put yourself in that situation, rate how confident you are in this moment about your ability to put yourself in that situation,

1

Not at all confident
100

Totally confident

\section{List Anxiety Provoking Situation}

3)

a) Anxiety rating (make sure it is at least 80 out of 100, with $100=$ extreme anxiety):

b) Rate how much you think deliberately putting yourself in this situation would be helpful in addressing anxiety about people:

1 100

Not at all helpful Extremely Helpful

c) If you were asked to go out right now and put yourself in that situation, rate how confident you are in this moment about your ability to put yourself in that situation,

1

Not at all confident
100

Totally confident

PECHS-Post 
In the space below we have listed three anxiety-provoking situations you identified earlier. For each situation, please re-rate (1) how much you think putting yourself into each particular situation (i.e., facing fear of that situation) would be helpful and (2) rate how confident you personally would be that you could deliberately put yourself in that situation.

\section{Anxiety Provoking Situation:}

1)

a) Rate how much you think deliberately putting yourself in this situation would be helpful in addressing your anxiety about people:

1

100

Not at all helpful

Extremely Helpful

b) If you were asked to go out right now and put yourself in that situation, rate how confident you are in this moment about your ability to put yourself in that situation,

1

Not at all confident
100

Totally confident

\section{Anxiety Provoking Situation}

2)

a) Rate how much you think deliberately putting yourself in this situation would be helpful in addressing your anxiety about people:

1

Not at all helpful
100

Extremely Helpful

b) If you were asked to go out right now and put yourself in that situation, rate how confident you are in this moment about your ability to put yourself in that situation, 


\section{Anxiety Provoking Situation}

3)

a) Rate how much you think deliberately putting yourself in this situation would be helpful in addressing anxiety about people:

1

100

Not at all helpful

Extremely Helpful

b) If you were asked to go out right now and put yourself in that situation, rate how confident you are in this moment about your ability to put yourself in that situation,

1

Not at all confident
100

Totally confident 


\section{ADAPTED CREDIBILITY \& EXPECTANCY QUESTIONNAIRE (CEQ)}

We would like you to indicate below how much you believe, right now, that psychotherapy would be helpful in reducing any psychological symptoms that you may be experiencing. If you are currently in psychotherapy, please respond with your current treatment in mind.

\section{One item expectancy measure:}

1. By the end of a course of therapy, how much improvement in your symptoms do you think would occur?

$\begin{array}{lllllllllll}0 \% & 10 \% & 20 \% & 30 \% & 40 \% & 50 \% & 60 \% & 70 \% & 80 \% & 90 \% & 100 \%\end{array}$

\section{Credibility scale:}

1. At this point, how logical does the therapy just presented to you seem?

\begin{tabular}{cccccccc}
1 & 3 & 4 & 5 & 6 & 7 & 8 & 9 \\
not at all logical & \multicolumn{9}{c}{ somewhat logical } & & & & very logical
\end{tabular}

2. At this point, how successfully do you think the treatment just presented would be in reducing your symptoms?

\begin{tabular}{cccccccc}
1 & 3 & 4 & 5 & 6 & 7 & 8 & 9 \\
not at all useful & \multicolumn{9}{c}{ somewhat useful } & & & very useful
\end{tabular}


3. How confident would you be in recommending the treatment just presented to a friend who experiences similar problems?

$\begin{array}{crrrrrrr}1 & 3 & 4 & 5 & 6 & 7 & 8 & 9 \\ \text { not at all confident } & & & \text { somewhat confident } & & & \text { very confident }\end{array}$


Below, each characteristic is followed by a seven-point scale that ranges from "not very" to "very." Please mark an "X" at the point on the scale that best represents how you viewed the therapist in the video you just saw. For example:

\section{FUNNY}

not very
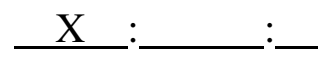

:

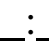

:

very

\section{WELL DRESSED}

not very

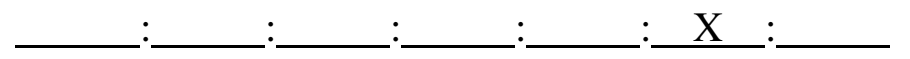

very

These ratings might show that the therapist did not joke around much, but was dressed well. Though all of the following characteristics we ask you to rate are desirable, therapists may differ in their strengths. We are interested in knowing how you view these differences. This form is confidential and will not be shown to your counselor.

1.

not very

2.

not very

3.

not very

4.

not very

5.
SINCERE

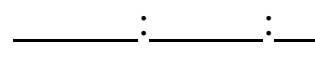

$:$

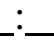

:

:

very

SKILLFUL

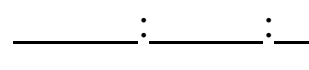

$:$

:

:

:

very

HONEST

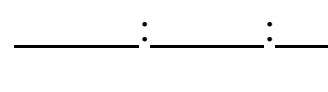

:

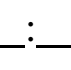

:

:

very

EXPERT

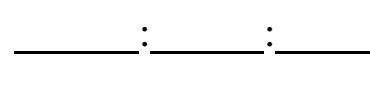

: : :

very

\section{LIKABLE}


not very

6.

not very

7.

not very

8.

not very

9.

not very

10.

not very

11.

not very

12.

not very
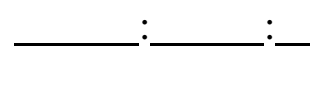

SOCIABLE

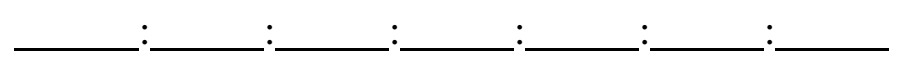

very

WARM

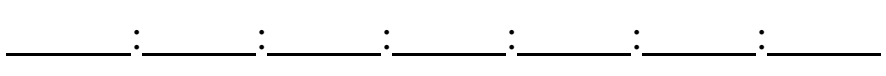

very

TRUSTWORTHY

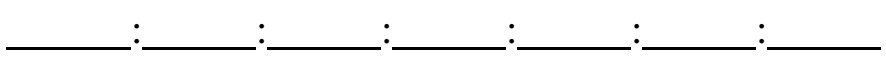

very

\section{EXPERIENCED}

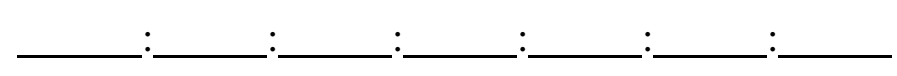

very

RELIABLE

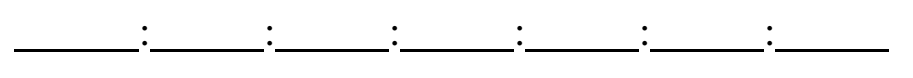

very

\section{PREPARED}

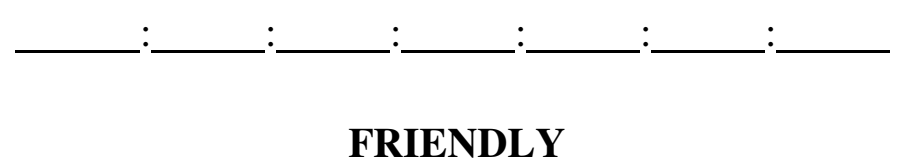

very

FRIENDLY

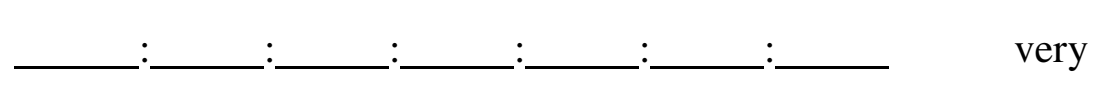




\section{APPENDIX H \\ BELIEFS ABOUT PSYCHOLOGICAL SERVICES SCALE (BAPS)}

Please read the following statements and rate them using the scale provided. Record the number that most accurately reflects your attitude toward seeking psychological help.

1 - Strongly disagree

2

3

4

5

6 - Strongly agree

1. If a good friend asked my advice about a serious problem, I would recommend that he/she see a psychologist.

2. I would be willing to confide my intimate concerns to a psychologist.

3. Seeing a psychologist is helpful when you are going through a difficult time.

4. At some future time, I might want to see a psychologist.

5. I would feel uneasy going to a psychologist because of what some people might think.

6. If I believed I were having a serious problem, my first inclination would be to see a psychologist.

7. Because of their training, psychologists can help you find solutions to your problems.

8. Going to a psychologist means that I am a weak person.

9. Psychologists are good to talk to because they do not blame you for the mistakes you have made.

10. Having received help from a psychologist stigmatizes a person's life. 
11. There are certain problems that should not be discussed with a stranger such as a psychologist.

12. I would see a psychologist if I were worried or upset for a long period of time.

13. Psychologists make people feel that they cannot deal with their problems.

14. It is good to talk to someone like a psychologist because everything you say is confidential.

15. Talking about problems with a psychologist strikes me as a poor way to get rid of emotional conflicts.

16. Psychologists provide valuable advice because of their knowledge about human behavior.

17. It is difficult to talk about personal issues with highly educated people such as psychologists.

18. If I thought I needed psychological help, I would get this help no matter who knew I was receiving assistance. 


\section{APPENDIX I \\ INTERPERSONAL EXPOSURE FREQUENCY SCALE}

At the experiment, you identified that was something you avoided or endured with anxiety.

How often in the past two weeks did you deliberately put yourself in this situation in order to help with your anxiety?

$$
\begin{array}{llllllllll}
1 & 2 & 3 & 4 & 5 & 6 & 7 & 8 & 9 & 10
\end{array}
$$

Never

Very often

At the experiment, you identified that was something you avoided or endured with anxiety.

How often in the past two weeks did you deliberately put yourself in this situation in order to help with your anxiety?

$\begin{array}{llllllllll}1 & 2 & 3 & 4 & 5 & 6 & 7 & 8 & 9 & 10\end{array}$

Never

Very often

At the experiment, you identified that was something you avoided or endured with anxiety.

How often in the past two weeks did you deliberately put yourself in this situation in order to help with your anxiety?

$\begin{array}{llllllllll}1 & 2 & 3 & 4 & 5 & 6 & 7 & 8 & 9 & 10\end{array}$

Never

Very often 
APPENDIX J

CBT REFERRAL LIST

\begin{tabular}{|c|l|}
\hline \multicolumn{2}{|c|}{ Cognitive Behavioral Therapy (CBT) Clinicians } \\
\hline \multicolumn{1}{|c|}{ Call 911 or go to your local emergency room } \\
\hline \multicolumn{1}{|c|}{$\begin{array}{l}\text { 1-800-273-TALK (1-800-273-8255) } \\
\text { Toll-free, 24-hour hotline of the National Suicide Prevention Lifeline }\end{array}$} \\
\hline Timothy Hope, PhD & $\begin{array}{l}\text { 433 West Street, Suite 5 } \\
\text { Amherst, MA 01002 } \\
\text { (413) 315-4417 }\end{array}$ \\
\hline Joseph Mangine, PhD & $\begin{array}{l}\text { 48 N Pleasant St Suite 205 } \\
\text { Amherst, MA 01002 } \\
\text { (413) 253-0237 }\end{array}$ \\
\hline Edward Plimpton, PhD & $\begin{array}{l}\text { 256 N. Pleasant Street } \\
\text { Amherst, MA 01002 } \\
\text { (413) 314-3182 }\end{array}$ \\
\hline Katherine Walsh, PhD, \\
LICSW
\end{tabular}




\section{APPENDIX K \\ CLIENT MOTIVATION FOR THERAPY SCALE (CMOTS)}

Imagine that you are currently involved in psychotherapy (or, if you are involved already, rate with that treatment in mind). Please indicate to what extent each of the following items corresponds to the reasons why you would be (or why you are) involved in therapy by circling the appropriate number.

1 - Does not correspond at all

2

3

4 - Corresponds moderately

5

6

7 - Corresponds exactly

1. For the pleasure I would experience when I feel completely absorbed in a therapy session.

$\begin{array}{lllllll}1 & 2 & 3 & 4 & 5 & 6 & 7\end{array}$

2. For the satisfaction I would have when I try to achieve my personal goals in the course of therapy.

$\begin{array}{lllllll}1 & 2 & 3 & 4 & 5 & 6 & 7\end{array}$

3. Because I experience pleasure and satisfaction when I learn new things about myself that I didn't know before.

$$
\begin{array}{lllllll}
1 & 2 & 3 & 4 & 5 & 6 & 7
\end{array}
$$

4. For the interest I have in understanding more about myself.

$\begin{array}{lllllll}1 & 2 & 3 & 4 & 5 & 6 & 7\end{array}$




\section{APPENDIX L \\ BRIEF SYMPTOM INVENTORY (BSI)}

Below is a list of problems and complaints that people sometimes have. Please read each one carefully, and circle the number to the right that best describes HOW MUCH THAT PROBLEM HAS DISTRESSED OR BOTHERED YOU DURING THE PAST 7 DAYS (week), INCLUDING TODAY. Circle only one number for each problem and do not skip any items. If you change your mind, erase your first mark carefully.

\begin{tabular}{|l|c|c|c|c|c|}
\hline HOW MUCH WERE YOU DISTRESSED BY: & all & Bit & $\begin{array}{c}\text { A little } \\
\text { ately }\end{array}$ & $\begin{array}{c}\text { Quite a } \\
\text { bit }\end{array}$ & Extremely \\
\hline 1. Nervousness or shakiness inside & 0 & 1 & 2 & 3 & 4 \\
\hline 2. Faintness or dizziness & 0 & 1 & 2 & 3 & 4 \\
\hline $\begin{array}{l}\text { 3. The idea that someone else can control your } \\
\text { thoughts }\end{array}$ & 0 & 1 & 2 & 3 & 4 \\
\hline $\begin{array}{l}\text { 4. Feeling others are to blame for most of your } \\
\text { troubles }\end{array}$ & 0 & 1 & 2 & 3 & 4 \\
\hline 5. Trouble remembering things & 0 & 1 & 2 & 3 & 4 \\
\hline 6. Feeling easily annoyed or irritated & 0 & 1 & 2 & 3 & 4 \\
\hline 7. Pains in heart or chest & 0 & 1 & 2 & 3 & 4 \\
\hline \begin{tabular}{l} 
8. Feeling afraid in open spaces or on the streets \\
\hline 9. Thoughts of ending your life
\end{tabular} & 0 & 1 & 2 & 3 & 4 \\
\hline 10. Feeling that most people cannot be trusted & 0 & 1 & 2 & 3 & 4 \\
\hline 11. Poor appetite & 0 & 1 & 2 & 3 & 4 \\
\hline 12. Suddenly scared for no reason & 0 & 1 & 2 & 3 & 4 \\
\hline 13. Temper outbursts that you could not control & 0 & 1 & 2 & 3 & 4 \\
\hline $\begin{array}{l}\text { 14. Feeling lonely even when you are with } \\
\text { people }\end{array}$ & 0 & 1 & 2 & 3 & 4 \\
\hline
\end{tabular}




\begin{tabular}{|c|c|c|c|c|c|}
\hline 15. Feeling blocked in getting things done & 0 & 1 & 2 & 3 & 4 \\
\hline 16. Feeling lonely & 0 & 1 & 2 & 3 & 4 \\
\hline 17. Feeling blue & 0 & 1 & 2 & 3 & 4 \\
\hline 18. Feeling no interest in things & 0 & 1 & 2 & 3 & 4 \\
\hline 19. Feeling fearful & 0 & 1 & 2 & 3 & 4 \\
\hline 20. Your feelings being easily hurt & 0 & 1 & 2 & 3 & 4 \\
\hline $\begin{array}{l}\text { 21.Feelings that people are unfriendly or dislike } \\
\text { you }\end{array}$ & 0 & 1 & 2 & 3 & 4 \\
\hline 22. Feeling inferior to others & 0 & 1 & 2 & 3 & 4 \\
\hline 23. Nausea or upset stomach & 0 & 1 & 2 & 3 & 4 \\
\hline $\begin{array}{l}\text { 24. Feeling that you are watched or talked about } \\
\text { by others }\end{array}$ & 0 & 1 & 2 & 3 & 4 \\
\hline 25. Trouble falling asleep & 0 & 1 & 2 & 3 & 4 \\
\hline $\begin{array}{l}\text { 26. Having to check and double-check what you } \\
\text { do }\end{array}$ & 0 & 1 & 2 & 3 & 4 \\
\hline 27. Difficulty making decisions & 0 & 1 & 2 & 3 & 4 \\
\hline $\begin{array}{l}\text { 28. Feeling afraid to travel on buses, subways, } \\
\text { or trains }\end{array}$ & 0 & 1 & 2 & 3 & 4 \\
\hline 29. Trouble getting your breath & 0 & 1 & 2 & 3 & 4 \\
\hline 30. Hot or cold spells & 0 & 1 & 2 & 3 & 4 \\
\hline $\begin{array}{l}\text { 31. Having to avoid certain things, places, or } \\
\text { activities because they frighten you }\end{array}$ & 0 & 1 & 2 & 3 & 4 \\
\hline 32. Your mind going blank & 0 & 1 & 2 & 3 & 4 \\
\hline 33. Numbness or tingling in parts of your body & 0 & 1 & 2 & 3 & 4 \\
\hline $\begin{array}{l}\text { 34. The idea that you should be punished for } \\
\text { your sins }\end{array}$ & 0 & 1 & 2 & 3 & 4 \\
\hline
\end{tabular}




\begin{tabular}{|c|c|c|c|c|c|}
\hline 35. Feeling hopeless about the future & 0 & 1 & 2 & 3 & 4 \\
\hline 36. Trouble concentrating & 0 & 1 & 2 & 3 & 4 \\
\hline 37. Feeling weak in parts of your body & 0 & 1 & 2 & 3 & 4 \\
\hline 38. Feeling tense or keyed up & 0 & 1 & 2 & 3 & 4 \\
\hline 39. Thoughts of death or dying & 0 & 1 & 2 & 3 & 4 \\
\hline $\begin{array}{l}\text { 40. Having urges to beat, injure, or harm } \\
\text { someone }\end{array}$ & 0 & 1 & 2 & 3 & 4 \\
\hline 41. Having urges to break or smash things & 0 & 1 & 2 & 3 & 4 \\
\hline 42. Feeling very self-conscious with others & 0 & 1 & 2 & 3 & 4 \\
\hline 43. Feeling uneasy in crowds & 0 & 1 & 2 & 3 & 4 \\
\hline 44. Never feeling close to another person & 0 & 1 & 2 & 3 & 4 \\
\hline 45. Spells of terror or panic & 0 & 1 & 2 & 3 & 4 \\
\hline 46. Getting into frequent arguments & 0 & 1 & 2 & 3 & 4 \\
\hline 47. Feeling nervous when you are left alone & 0 & 1 & 2 & 3 & 4 \\
\hline $\begin{array}{l}\text { 48. Others not giving you proper credit for your } \\
\text { achievements }\end{array}$ & 0 & 1 & 2 & 3 & 4 \\
\hline 49. Feeling so restless you couldn't sit still & 0 & 1 & 2 & 3 & 4 \\
\hline 50. Feelings of worthlessness & 0 & 1 & 2 & 3 & 4 \\
\hline $\begin{array}{l}\text { 51. Feeling that people will take advantage of } \\
\text { you if you let them }\end{array}$ & 0 & 1 & 2 & 3 & 4 \\
\hline 52. Feelings of guilt & 0 & 1 & 2 & 3 & 4 \\
\hline $\begin{array}{l}\text { 53. The idea that something is wrong with your } \\
\text { mind }\end{array}$ & 0 & 1 & 2 & 3 & 4 \\
\hline
\end{tabular}




\section{APPENDIX M}

\section{POSITIVE AND NEGATIVE AFFECT SCHEDULE (PANAS)}

This scale consists of a number of words that describe different feelings and emotions. Read each item and then mark the appropriate answer in the space next to that word. Indicate to what extent you feel this way right now, that is, at the present moment.

$1-$ Very slightly or not at all

2 - A little

3 - Moderately

4 - Quite a bit

5 - Extremely

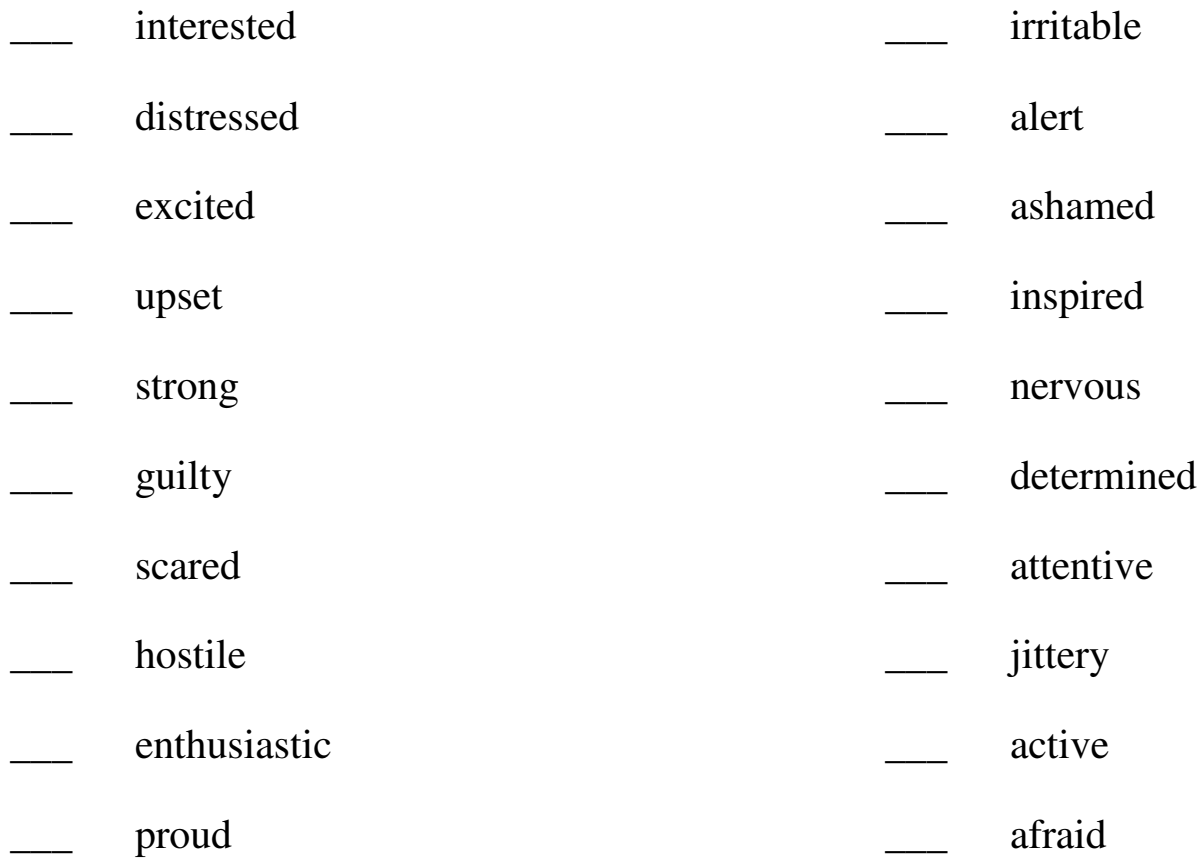




\section{APPENDIX N \\ UNIVERSITY OF RHODE ISLAND CHANGE ASSESSMENT (URICA) ACTION SUBSCALE}

Each statement below describes how a person might feel when starting therapy or approaching problems in their lives. Please indicate the extent to which you tend to agree or disagree with each statement. In each case, make your choice in terms of how you feel right now, not what you have felt in the past or would like to feel. For all statements that refer to your "problem," answer in terms of problems related to social anxiety.

There are five possible responses to each of the items in the questionnaire:

1 - Strongly Disagree

2 - Disagree

3 - Undecided

4 - Agree

5 - Strongly Agree

\section{Circle the number that best describes how much you agree or disagree with each} statement.

1. I am doing something about the social anxiety that had been bothering me.

$\begin{array}{lllll}1 & 2 & 3 & 4 & 5\end{array}$

2. I am finally doing some work on my problem.

$\begin{array}{lllll}1 & 2 & 3 & 4 & 5\end{array}$

3. At times my social anxiety is difficult, but I'm working on it.

$\begin{array}{lllll}1 & 2 & 3 & 4 & 5\end{array}$

4. I am really working hard to change.

$\begin{array}{lllll}1 & 2 & 3 & 4 & 5\end{array}$


5. Even though I'm not always successful in changing, I am at least working on my social anxiety.

$\begin{array}{lllll}1 & 2 & 3 & 4 & 5\end{array}$

6. I have started working on my social anxiety, but I would like help.

$\begin{array}{lllll}1 & 2 & 3 & 4 & 5\end{array}$

7. Anyone can talk about changing, I'm actually doing something about it.

$\begin{array}{lllll}1 & 2 & 3 & 4 & 5\end{array}$

8. I am actively working on my problem.

$\begin{array}{lllll}1 & 2 & 3 & 4 & 5\end{array}$




\section{APPENDIX O \\ DEMOGRAPHIC QUESTIONNAIRE}

Please indicate your answers to the following items.

1. Age:

2. Sex:

Male

Female

3. Ethnicity (select all that apply):

Black/Afro-Caribbean/African

Asian (e.g., South Asian, East Asian, Southeast Asian)

White/European

Hispanic/Latin American

Native American or Alaska Native

Native Hawaiian or Other Pacific Islander

Biracial/multiracial

Other (specify

4. Year in college:

$$
\begin{aligned}
& 1^{\text {st }} \\
& 2^{\text {nd }} \\
& 3^{\text {rd }} \\
& 4^{\text {th }} \\
& 5^{\text {th }} \\
& 6^{\text {th }} \text { or higher }
\end{aligned}
$$

5. Average annual family household income (check the category that best applies): 
Less than $\$ 25,000$

$\$ 25,001-\$ 50,000$

$\$ 50,001-\$ 75,000$

$\$ 75,001$ - $\$ 100,000$

$\$ 100,001-\$ 125,000$

$\$ 125,001-\$ 150,000$

$\$ 150,001-\$ 175,000$

$\$ 175,001-\$ 200,000$

$\$ 200,001+$

6. Marital status:

Single

Married

Divorced

Widowed

7. Student/occupational status:

Full-time student, not employed

Full-time student, employed part-time

Full-time student, employed full-time

Part-time student, not employed

Part-time student, employed part-time

Part-time student, employed full-time 


\section{APPENDIX P \\ CONCEPTUALIZATION OF SOCIAL ANXIETY}

Please indicate how much you agree with the following statements, using the scale provided:

1 - Strongly disagree

2 - Disagree

3 - Somewhat disagree

4 - Neutral/no opinion

5 - Somewhat agree

6 - Agree

7 - Strongly agree

1. I believe that my tendency to become anxious in social situations is related to biological factors, such as the chemicals in my brain.

$\begin{array}{lllllll}1 & 2 & 3 & 4 & 5 & 6 & 7\end{array}$

2. I believe that my tendency to become anxious in social situations is related to interpersonal factors, such as difficulty relating to those around me.

$\begin{array}{lllllll}1 & 2 & 3 & 4 & 5 & 6 & 7\end{array}$

3. I believe that my tendency to become anxious in social situations is related to my own thoughts or beliefs, such thinking that I will say something stupid.

$\begin{array}{lllllll}1 & 2 & 3 & 4 & 5 & 6 & 7\end{array}$

4. I believe that my tendency to become anxious in social situations is related to my emotions, such as difficulty regulating my emotional reactions when around others.

$\begin{array}{lllll}1 & 2 & 3 & 4 & 5\end{array}$




\section{APPENDIX Q PSYCHOTHERAPY HISTORY}

Please indicate your answers to the following items.

1. Are you currently in psychotherapy for any psychological difficulties?

Yes

No

If Yes, please answer item 2. If No, please skip to and answer item 3.

2. How satisfied are you with your current treatment for any psychological difficulties?

1 - Very satisfied

2 - Satisfied

3 - Somewhat satisfied

4 - Neutral/ no opinion

5 - Somewhat dissatisfied

6 - Dissatisfied

7 - Very Dissatisfied

3. Are you actively considering psychotherapy for any psychological difficulties?

Yes

No

4. Are you currently in psychotherapy for social anxiety concerns?

Yes

No

If Yes, please answer item 5. If No, please skip to and answer item 6.

5. How satisfied are you with your current treatment for social anxiety concerns?

1 - Very satisfied

2 - Satisfied

3 - Somewhat satisfied

4 - Neutral/ no opinion

5 - Somewhat dissatisfied 
6 - Dissatisfied

7 - Very Dissatisfied

6. Are you actively considering psychotherapy for social anxiety concerns?

Yes

No

7. Have you ever been in psychotherapy before for any psychological difficulties?

Yes

No

If yes, please answer items 8 and 9.

8. How many times have you previously been in psychotherapy for any psychological difficulties (separate courses of treatment)?

9. On average, how satisfied have you been with your psychotherapy experience(s) for any psychological difficulties?

1 - Very satisfied

2 - Satisfied

3 - Somewhat satisfied

4 - Neutral/ no opinion

5 - Somewhat dissatisfied

6 - Dissatisfied

7 - Very Dissatisfied

10. Have you ever been in psychotherapy before for social anxiety concerns?

Yes

No

If yes, please answer items 8 and 9 .

11. How many times have you previously been in psychotherapy for social anxiety concerns (separate courses of treatment)? 
12. On average, how satisfied have you been with your psychotherapy experience(s) for social anxiety concerns?

1 - Very satisfied

2 - Satisfied

3 - Somewhat satisfied

4 - Neutral/ no opinion

5 - Somewhat dissatisfied

6 - Dissatisfied

7 - Very Dissatisfied 


\section{REFERENCES}

Ægisdóttir, S., \& Gerstein, L. (2009). Beliefs About Psychological Services (BAPS): Development and psychometric properties. Counselling Psychology Quarterly, 22, 197-219. doi:10.1080/09515070903157347

Ahmed, M., \& Westra, H. A. (2009). Impact of a treatment rationale on expectancy and engagement in cognitive behavioral therapy for social anxiety. Cognitive Therapy and Research, 33, 314-322. doi:10.1007/s10608-008-9182-1

Anderson, T., Lunnen, K. M., \& Ogles, B. M. (2010). Putting models and techniques in context. In B. L. Duncan, S. D. Miller, B. E. Wampold, \& M. A. Hubble (Eds.), The heart and soul of change: Delivering what works in therapy (2nd ed.) (pp. 143-166). Washington, DC US: American Psychological Association. doi:10.1037/12075-005

Arnkoff, D. B., Glass, C. R., \& Shapiro, S. J. (2002). Expectations and preferences. In J. C. Norcross (Ed.), Psychotherapy relationships that work: Therapists contributions and responsiveness to patients (pp. 335-356). New York, NY: Oxford University Press.

Borkovec, T. D., Newman, M. G., Pincus, A. L., \& Lytle, R. (2002). A component analysis of cognitive-behavioral therapy for generalized anxiety disorders and the role of interpersonal problems. Journal of Consulting and Clinical Psychology, 70, 288-298. doi: 10.1037/0022-006X.70.2.288

Chaiken, S., \& Eagly, A. H. (1976). Communication modality as a determinant of message persuasiveness and message comprehensibility. Journal of Personality and Social Psychology, 34, 605-614. doi:10.1037/0022-3514.34.4.605

Cohen, J. (1988). Statistical power analysis for the behavioral sciences (2nd ed.). Hillside, NJ: Lawrence Erlbaum. 
Collins, K. A., Westra, H. A., Dozois, D. J. A., \& Stewart, S. H. (2005). The validity of the brief version of the fear of negative evaluation scale. Journal of Anxiety Disorders, 19, 345-359. doi:10.1016/S0887-6185(04)00022-2

Constantino, M. J. (2012). Believing is seeing: An evolving research program on patients' psychotherapy expectations. Psychotherapy Research, 22, 127-138. doi: $10.1080 / 10503307.2012 .663512$

Constantino, M. J., Ametrano, R. M., \& Greenberg, R. P. (2012). Clinician interventions and participant characteristics that foster adaptive patient expectations for psychotherapy and psychotherapeutic change. Psychotherapy, 49, 557-569. doi:10.1037/a0029440

Constantino, M. J., Boswell, J. F., Bernecker, S. L., \& Castonguay, L. G. (2013). Contextresponsive psychotherapy integration as a framework for a unified clinical science: Conceptual and empirical considerations. Journal of Unified Psychotherapy and Clinical Science, 2, 1-20.

Constantino, M. J., Glass, C. R., Arnkoff, D. B., Ametrano, R. M., \& Smith, J. Z. (2011). Expectations. In J. C. Norcross (Ed.), Psychotherapy relationships that work: Therapist contributions and responsiveness to patients (2nd ed.; pp. 354-376). New York: Oxford University Press, Inc. doi: 10.1093/acproso 9780199737208.003 .0018

Constantino, M. J., Klein, R., Smith-Hansen, L., \& Greenberg, R. P. (2009, October). Augmenting cognitive therapy for depression with an Expectancy Enhancement module: Preliminary efficacy. Paper presented at the meeting of the Canadian Chapter of the Society for Psychotherapy Research, Montreal, Canada. 
Constantino, M. J., \& Westra, H. A. (2012). An expectancy-based approach to facilitating corrective experiences in psychotherapy. In L. G. Castonguay \& C. E. Hill (Eds.), Transformation in psychotherapy: Corrective experiences across cognitive, behavioral, humanistic, and psychodynamic approaches (pp. 121-139). Washington, DC: American Psychological Association.

Corrigan, J. D., \& Schmidt, L. D. (1983). Development and validation of revisions in the counselor rating form. Journal of Counseling Psychology, 30, 64-75. doi:10.1037//0022-0167.30.1.64

Deci, E. L., \& Ryan, R. M. (1985). The general causality orientations scale: Self determinationin personality. Journal of Research in Personality, 19, 109-134. doi:10.1016/0096566(85)90023-6

Derogatis, L. R., \& Melisaratos, N. (1983). The brief symptom inventory: An introductory report. Psychological Medicine, 13, 595-605. doi:10.1017/S0033291700048017

Devilly, G. J., \& Borkovec, T. D. (2000). Psychometric properties of the credibility/expectancy questionnaire. Journal of Behavioral Therapy and Experimental Psychiatry, 31, 73-86. doi:10.1016/S0005-7916(00)00012-4

DiClemente, C. C., \& Prochaska, J. O. (1982). Self-change and therapy change of smoking behavior: A comparison of processes of change in cessation and maintenance. Addictive Behaviors, 7, 133-142. doi:10.1016/0306-4603(82)90038

Dozois, D. J. A., \& Westra, H. A. (2005). Development of the anxiety change expectancy scale (ACES) and validation in college, community, and clinical samples.

Behaviour Research and Therapy, 43, 1655-1672. doi:10.1016/j.brat.2004.12.001 
Epperson, D. L., \& Pecnik, J. A. (1985). Counselor rating Form—Short version: Further validation and comparison to the long form. Journal of Counseling Psychology, 32, 143-146. doi:10.1037//0022-0167.32.1.143

Frank, J. D. (1961). Persuasion and healing: A comparative study of psychotherapy. Oxford, England: Johns Hopkins University Press.

Frank, J., \& Frank, J. B. (1991). Persuasion and healing: A comparative study of psychotherapy ( $3^{\text {rd }}$ ed.). Baltimore: Johns Hopkins University Press.

Goldfried, M. R. (1980). Toward the delineation of therapeutic change principles. American Psychologist, 35, 991-999. doi:10.1037/0003-066X.35.11.991

Goldman, R. E., Hilsenroth, M. J., Owen, J. J., \& Gold, J. R. Psychotherapy integration and alliance: Use of cognitive-behavioral techniques within a short-term psychodynamic treatment model. Journal of Psychotherapy Integration, 23, 373-385. doi:10.1037/a0034363

Greenberg, R. P., Constantino, M. J., \& Bruce, N. (2006). Are patient expectations still relevant for psychotherapy process and outcome? Clinical Psychology Review, 26, 657-678. doi:10.1016/j.cpr.2005.03.002

Hoehn-Saric, R. R., Frank, J. D., Imber, S. D., Nash, E. H., Stone, A. R., \& Battle, C. C. (1964). Systematic preparation of patients for psychotherapy: I. Effects on therapy behavior and outcome. Journal of Psychiatric Research, 2, 267-281. doi:10.1016/00223956(64)90013-5

Horvath, P. (1990) Treatment expectancy as a function of the amount of information presented in therapeutic rationales. Journal of Clinical Psychology, 46, 636-642. doi:10.1002/10974679(199009)46:5<636::AID-JCLP2270460516>3.0.CO;2-U 
Kazdin, A. E., \& Krouse, R. (1983). The impact of variations in treatment rationales on expectancies for therapeutic change. Behavior Therapy, 14, 657-671. doi:10.1016/S00057894(83)80058-6

Leary, M. R. (1983). A brief version of the Fear of Negative Evaluation Scale. Personality and Social Psychology Bulletin, 9, 371-376. doi:10.1177/0146167283093007

McConnaughy, E. A., Prochaska, J. O., \& Velicer, W. F. (1983). Stages of change in psychotherapy: Measurement and sample profiles. Psychotherapy: Theory, Research \& Practice, 20, 368-375.

McKee, S. A., Carroll, K.M., Sinha, R., Robinson, J. E., Nich, C., Cavallo, D., \& O’Malley, S. (2007). Enhancing brief cognitive-behavioral therapy with motivational enhancement techniques in cocaine user. Drug and Alcohol Dependence, 91, 97-101. doi:10.1016/j.drugalcdep.2007.05.006

Miller, W.R., \& Rollnick, S. (2002). Motivational interviewing: Preparing people for change(2nd ed.). New York: Guilford Press.

Miller, W.R., Zweben, A., DiClemente, C.C., Rychtarik, R.G. (1992). Motivational Enhancement Therapy Manual. DHHS Publication No. (ADM) 92-1894.

Pelletier, L. G., Tuson, K. M., \& Haddad, N. K. (1997). Client motivation for therapy scale: A measure of intrinsic motivation, extrinsic motivation, and amotivation for therapy. Journal of Personality Assessment, 68, 414-435.

doi:10.1207/s15327752jpa6802_11 
Ponterotto, J. G., \& Furlong, M. J. (1985). Evaluating counselor effectiveness: A critical review of rating scale instruments. Journal of Counseling Psychology, 32, 597616. doi:10.1037/0022-0167.32.4.597

Price, M., Anderson, P., Henrich, C., \& Rothbaum, B. O. (2008). Greater expectations: Hierarchical linear modeling of expectancies as a predictor of treatment outcome. Behavior Therapy, 39, 398-405. doi:10.1016/j.beth.2007.12.002

Rosen, G. M. (1975). Subjects' initial therapeutic expectancies towards systematic desensitization as a function of varied instructional sets. Behavior Therapy, 6 , 230-237. doi:10.1016/S0005-7894(75)80145-6

Vogel, P. A., Hansen, B., Stiles, T. C., \& Götestam, K. (2006). Treatment motivation, treatment expectancy, and helping alliance as predictors of outcome in cognitive behavioral treatment of OCD. Journal of Behavior Therapy And Experimental Psychiatry, 37, 247-255. doi:10.1016/j.jbtep.2005.12.001

Watson, D., Clark, L. A., \& Tellegen, A. (1988). Development and validation of brief measures of positive and negative affect: The PANAS scales. Journal of Personality and Social Psychology, 54, 1063-1070. doi:10.1037//00223514.54.6.1063

Weinberger, L., \& Eig, A. (1999). Expectancies: The ignored common factor in psychotherapy. In I. Kirsch (Ed.), How expectancies shape experience (pp. 357 382). Washington, DC: American Psychological Association. doi:10.1037/10332-015 
Westra, H. A., Dozois, D. J. A., \& Marcus, M. (2007). Early improvement, expectancy, and homework compliance as predictors of outcome in cognitive behavioural therapy for anxiety. Journal of Consulting and Clinical Psychology, 75(3), 363-373.

Wollersheim, J. P., Bordewick, M., Knapp, M., McLellarn, R., \& Paul, W. (1982). The influence of therapy rationales upon perceptions of clinical populations. Cognitive Therapy and Research, 6, 167-172. doi:10.1007/BF01183889 